\title{
E-voting en Colombia: avances y desafíos en la implementación ${ }^{* *-* * * *}$
}

\author{
E-voting in Colombia: progress \\ and challenges in its implementation
}

RESUMEN

En Colombia, una de las tareas pendientes del legislador es la adecuación y modernización de las reglas que gobiernan el proceso electoral en todas sus etapas, y dentro del cual tiene un lugar importante la puesta en marcha del voto electrónico. Las reglas que rigen el sistema electoral en Colombia están determinadas en la Constitución, sus reformas, las leyes y en el código electoral (Dcto. 2241 de 1986). A las reglas dispuestas en el texto original de la Constitución de 1991 se han adicionado principios rectores que deben guiar la organización y funcionamiento de las organizaciones políticas. Todas estas nuevas figuras se han venido aplicando junto con las reglas de un código electoral que no está acorde con las modificaciones constitucionales, entre las que destaca el mandato de la puesta en marcha del voto electrónico. La implementación del voto electrónico en Colombia enfrenta los retos de la modernización del proceso electoral, de la voluntad política de las mayorías parlamentarias, el respaldo económico y financiero del poder ejecutivo, la capacitación de la ciudadanía y la confianza de la misma en el proceso y las autoridades electorales. En el presente trabajo se realiza un análisis del voto electrónico y los retos para su implementación teniendo en cuenta el escenario que suponen las reglas sobre las elecciones y la conformación del poder político en nuestro país.

Doctora en Derecho Constitucional de la Universidad de Alicante, España. Abogada y especialista en Derecho Constitucional y Parlamentario de la Universidad Externado de Colombia. Profesora titular de Derecho Constitucional de la Universidad Externado de Colombia. Bogotá, Colombia. Contacto: floralba.padron@uexternado.edu.co

Recibido el 20 de octubre de 2017, aprobado el 4 de abril de 2018.

Para citar el artículo: PADRÓN PARDO, F. E-voting en Colombia: avances y desafíos en la implementación. En Revista Derecho del Estado, Universidad Externado de Colombia. N. ${ }^{\circ} 42$, enero-abril de 2019, pp. 211-248.

DOI: https://doi.org/10.18601/01229893.n42.08

*** La autora agradece la colaboración de Juan Sebastián Narváez Quintero en la revisión formal y material del presente escrito. 
PALABRAS CLAVE

Democracia representativa, derecho al sufragio, voto electrónico, tecnologías de la información y de las comunicaciones, participación ciudadana.

\section{ABSTRACT}

In Colombia, one of the challenges of the legislative branch y to upgrade the legal measures for electoral progress and the modernization of the constitutional rules that govern the electoral process in all its stages, and in which the launching of electronic voting has an important place. The rules that govern the Electoral System in Colombia are in the Constitution, its reforms, the laws and the electoral code (Decree 2241 of 1986). To the rules set forth in the original text of the 1991 Constitution, guiding principles have been added that should guide the organization and functioning of political organizations. All these new figures have been submitted to apply with the rules of an electoral code that is not consistent with the constitutional changes, among which we highlight the mandate of the implementation of electronic voting. The implementation of electronic voting in Colombia has the challenges of the modernization of the electoral process in Colombia, the political will of the major parliamentarians, the economic and financial support of the executive power, the training of citizenship and its confidence in the process and electoral authorities. In the present work is done an analysis of the electronic vote and the challenges for its adaptation taking into account the rules on the elections and the conformation of the political power in Colombia.

\section{KEYWORDS}

Representative democracy, right to suffrage, electronic voting, information and communication technologies, citizen participation.

SUMARIO

Introducción. 1. Las características del voto en Colombia. 2. Precisiones sobre el concepto y categorías del voto electrónico. 3. Marco normativo y jurisprudencial del voto electrónico en Colombia. 4. Estado de implementación del voto electrónico en Colombia 4.1. Algunos estándares internacionales sobre mecanismos de gobierno y participación digital. 4.2. Una mirada comparativa al desarrollo del voto electrónico en otros países. 4.3. Etapas y retos para la implementación del voto electrónico en Colombia. 4.4. Estado actual del voto electrónico en Colombia. Conclusiones. Referencias. 


\section{INTRODUCCIÓN}

La implementación de mecanismos de votación electrónica o por medio de máquinas y aparatos no es un tema de discusión reciente. Ya en el siglo XIX surgieron propuestas "para hacer de las elecciones algo más eficientes y teóricamente seguras, con el uso de tecnologías de votación automatizada" de forma que "los inventores comenzaron a buscar diversas maneras de contener fraudes electorales, facilitar la selección del votante y el conteo de los

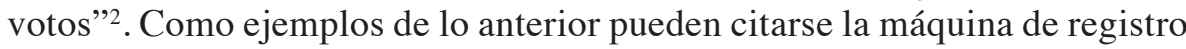
de voto electrográfico inventada por Thomas Alva Edison en 1869, la cabina automática de Myers desarrollada en Nueva York en 1891 y las máquinas de perforación de Hollerith de 1930, entre otros mecanismos como los sistemas de voto por teléfono, los sistemas de escaneo público, las máquinas DRE y demás innovaciones hechas hasta hoy, como el voto por internet ${ }^{3}$.

En Colombia, una de las tareas pendientes del legislador es la reforma del sistema electoral colombiano, es decir, la adecuación y modernización de las reglas que regulan el proceso electoral en todas sus etapas (previa, electoral propiamente dicha y posterior $)^{4}$, en el que tiene un lugar importante la puesta en marcha del voto electrónico. Las normas que rigen el sistema electoral en Colombia están determinadas en la Constitución (con las reformas introducidas en 2003 y 2009), en las leyes ${ }^{5}$ y en una norma preconstitucional, el código electoral (Dcto. 2241 de 1986).

A las reglas constitucionales dispuestas en el texto original de la Constitución de 1991 se han adicionado principios rectores que deben guiar la organización y funcionamiento de las organizaciones políticas, el sistema de listas abiertas o cerradas, el umbral, la introducción del funcionamiento de bancadas en todas las corporaciones de elección popular y la cifra repartidora como regla para asignar las curules. Todas estas nuevas figuras se han venido aplicando junto con las reglas de un código electoral anterior a la Constitución de 1991 y que no está acorde con esta y sus modificaciones, entre las que destaca el mandato de la puesta en marcha del voto electrónico.

1 Ruiz ZúÑIGA, M. M. El voto electrónico. México: Universidad de Xalapa, 2014, 121.

2 Ibíd.

3 Ibíd.

4 "Los procesos pueden ser analizados en tres etapas: Pre-Electoral: corresponde a los acontecimientos preparatorios del evento electoral, como la inscripción de cédulas y candidaturas, el nombramiento de jurados, testigos, claveros, etc., y aspectos relacionados con la parte logística, como la financiación de partidos y movimientos políticos y la reposición de votos. Electoral: corresponde al desarrollo del día de elecciones, y Post-Electoral: equivale al proceso de escrutinios y declaratoria de elección". ReYes GonZÁLEz, G. F. Régimen electoral y de partidos políticos en Colombia. 2. ed. Bogotá: Konrad Adenauer Stiftung, 2007, 412.

5 Entre las leyes expedidas por el Congreso de la República en materia electoral se encuentran la 130 de 1994, la 131 de 1994, la 163 de 1994, la 403 de 1997, la 616 de 2000, la 741 de 2002, la 892 de 2004, la 996 de 2005 y la 1475 de 2011. 
La implementación del voto electrónico comparte el complejo camino de la modernización del sistema electoral en Colombia, así como los problemas de la voluntad política de las mayorías parlamentarias y del respaldo económico y financiero del poder ejecutivo. No es posible hacer un análisis del voto electrónico sin tener en cuenta que hace parte de este complicado escenario de las reglas sobre las elecciones y la conformación del poder político en Colombia.

La implementación de los sistemas electrónicos enfrenta dos grandes desafíos: por un lado, devolverle a la ciudadanía la confianza en los resultados electorales, limpios y transparentes, no susceptibles de corrupción (suplantación de votantes, votos de personas fallecidas, mantenimiento de las características de secreto e inviolable); por otro lado, disminuir la abstención electoral ${ }^{6}$. En este último objetivo debe tenerse en cuenta que la inclusión de mecanismos electrónicos no puede significar una barrera adicional para los ciudadanos que no han entrado en la era digital (brecha digital) ${ }^{7}$. Dicho de otra manera, el voto electrónico debe servir es, por el contrario, para disminuir la abstención, y su implementación debe contribuir al trato igualitario de los ciudadanos ${ }^{8}$.

6 En las elecciones presidenciales para el periodo 2014-2018, en la primera vuelta el porcentaje de abstención fue del $60 \%$. El censo electoral vigente era de 32.975 .158 personas habilitadas para votar, de las cuales solo 13.216.402 ejercieron su derecho (el equivalente a un $40 \%$ del censo nacional electoral). Datos disponibles en: https://www.registraduria.gov.co/Elecciones-2014,1995-.html (Consultado el 16 de mayo de 2018).

7 En 2012,21.645 niños en Colombia vivían en casas con acceso a internet. Información del Banco Mundial, disponible en: http://www1.worldbank.org/poverty/visualizeinequality/LAC/ cov_maps.html (Consultado el 17 de mayo de 2018)

8 A 25 de mayo de 2014, fecha de la primera vuelta de las presidenciales, conformaban el censo electoral 32.975.158 ciudadanos residentes en el país y en el exterior, según el último censo realizado por el Departamento Administrativo Nacional de Estadística (DANE) y divulgado en la página web de la Registraduría Nacional del Estado Civil. En las presidenciales realizadas en 2014 votaron 15.794 .940 ciudadanos, es decir, el $47.89 \%$ del censo electoral, y en las parlamentarias de 2014 votaron 14.310.367 ciudadanos, lo que corresponde al $43,6 \%$ del censo electoral. Según el documento del DANE "Encuesta de cultura política 2008 - Informe de resultados", el 37,95\% de los encuestados no participa por falta de tiempo; el 35,47\% por falta de información; al 22,96\% no le interesa; el 5,78 dice que no existen mecanismos adecuados, y el 5,48\% desconfía de las instituciones. El 59,58\% de los colombianos manifestó votar siempre que hay elecciones en el país, el 25,75\% respondió que solo vota a veces y el 14,67\% informó no haber votado. Datos disponibles en: https:/www.dane.gov.co/files/ investigaciones/ecpolitica/informe_ECP_08.pdf (Consultado el 16 de mayo de 2018). En el caso del plebiscito celebrado en octubre de 2016 para la refrendación del "Acuerdo Final para la terminación del conflicto y la construcción de una paz estable y duradera", según las cifras publicadas en la página web de la Registraduría Nacional del Estado Civil, la participación ascendió únicamente al 37,43\% del censo electoral, es decir, apenas 13.066.047 de 34.899.945 personas habilitadas, con una abstención del 62,57\%. Datos disponibles en: https://elecciones. registraduria.gov.co/pre_plebis_2016/99PL/DPLzzzzzzzzzzzzzZzZz_L1.htm (Consultado el 16 de mayo de 2018). 
En el presente trabajo se hace una presentación de la regulación legal y jurisprudencial del voto electrónico en el país, realizando precisiones conceptuales sobre los mecanismos electrónicos de votación, los presupuestos y retos de su implementación, así como su estado actual.

\section{LAS CARACTERÍSTICAS DEL VOTO EN COLOMBIA}

En el ordenamiento constitucional colombiano el voto es un deber ciudadano (art.95), un derecho fundamental y un mecanismo de participación ciudadana (arts. 40 y 103), por lo que el derecho al voto goza de una protección reforzada a través de la acción de tutela y de una reserva de ley estatutaria ${ }^{9}$. Los ciudadanos pueden ejercer libremente el derecho al voto y las autoridades están obligadas a garantizar su ejercicio, no pudiendo impedirlo ni presionar o dirigir la forma como debe hacerse efectivo. En Colombia, el voto tiene tres características esenciales: es individual, libre y secreto.

El Estado es quien debe proteger, auspiciar y fomentar el derecho al sufragio, no solo por cuanto a este le corresponde, como fin esencial, "garantizar la efectividad de los principios, derechos y deberes consagrados en la Constitución", sino también porque el ejercicio y efectividad del sufragio, dada su especial característica de derecho-deber (art. 258 C.P.), corresponde a una responsabilidad anexa a la democracia, que es presupuesto esencial del Estado social de derecho.

Por consiguiente, de una parte, le corresponde al Congreso señalar las reglas que lo desarrollan y que definen sus límites y alcances en la vida democrática (por medio de una ley estatutaria, la cual requiere una mayoría cualificada y la observancia de un trámite especial); de otra, a las autoridades electorales les compete implementar los medios y organizar las estrategias que permitan su efectivo ejercicio, y evitar las posibles desviaciones de la voluntad de los electores. Entre las autoridades electorales ${ }^{10}$ se cuentan principalmente la Registraduría Nacional del Estado Civil y el Consejo Nacional Electoral, correspondiéndole a la primera la identificación de los ciudadanos y dirigir y

9 En Colombia existen varios tipos de ley: ordinaria, orgánica y estatutaria. El artículo 152 de la Constitución establece: "Mediante leyes estatutarias, el Congreso de la República regulará entre otras las siguientes materias: a) Derechos y deberes fundamentales de las personas y los procedimientos y recursos para su protección; d) Instituciones y mecanismos de participación ciudadana". Sobre el núcleo esencial del derecho al voto y su tutela judicial efectiva ver, entre otras, las sentencias T-049 de 1993, C-179 de 1994 y SU-747 de 1998. Ver Cuervo Rubio, A. F. Las leyes estatutarias en el ordenamiento jurídico colombiano. Bogotá: Universidad Externado de Colombia, 2017.

10 Según el artículo 9. el código electoral, Decreto 2241 de 1986, "La organización electoral estará a cargo: a) Del Consejo Nacional Electoral; b) Del Registrador Nacional del Estado Civil; c) De los delegados del Registrador Nacional del Estado Civil; d) De los Registradores Distritales, Municipales y Auxiliares, y e) De los Delegados de los Registradores Distritales y Municipales". 
organizar el proceso electoral de acuerdo con la ley (arts. 120, 150-23, 152-c, 265 y 266 C.P. $)^{11}$.

En la Constitución Política, el voto no solo sirve para activar el circuito de la democracia representativa (elegir a los representantes de las corporaciones de elección popular y a los de los cargos uninominales) sino que también se ejerce en la activación de los mecanismos de participación ciudadana (referendo, consulta popular, plebiscito, revocatoria del mandato, consulta interna de organizaciones políticas). La voluntad de los ciudadanos se manifiesta a través del voto, como lo ha expuesto la Corte Constitucional en la sentencia C-337 de 1997: "Si el sufragio es medio esencial para la participación del ciudadano en el ejercicio del poder político, es deber del Estado 'facilitar la participación de todos en las decisiones que los afectan' (art. 2 C.P.) e implementar los 'mecanismos de votación que otorguen más y mejores garantías para el libre ejercicio de ese derecho a los ciudadanos' (art. 258 C.P.)".

El voto en cualquiera de sus manifestaciones -por medio de tarjetas electorales, urnas físicas y conteo manual o hecho de manera electrónica, a través de dispositivos fijos o remotos ${ }^{12}-$ tiene las anteriores características, goza de

11 En ese sentido se ha pronunciado la Corte Constitucional en la sentencia C-511 de 1999: "Pero es necesario advertir que la actividad material que cumple la Registraduría del Estado Civil, que se traduce en el manejo del proceso de identificación, la dirección y la organización de las elecciones, constituye indudablemente un servicio público cuya regulación normativa está deferida a la ley (C.P. art. L4, 40, 95, 131, 258 y 266). Sin embargo, dicha actividad material, dirigida a los anotados propósitos, aun cuando tiene incidencia no puede confundirse con la habilitación que otorga la cédula para el ejercicio de los derechos políticos y, además, como medio eficaz para el reconocimiento de la personalidad humana y, desde luego, de la calidad de ciudadano. Desde una perspectiva funcional estima la Corte que, según la Constitución que nos rige, la actividad electoral no corresponde técnicamente al ejercicio de la función administrativa asignada a la Rama Ejecutiva del poder público, como ocurría en el pasado. Hoy en día, la 'Organización Electoral', integrada por el Consejo Nacional Electoral, la Registraduría Nacional del Estado Civil y los demás organismos que establezca la ley, es autónoma e independiente; tiene definida su propia naturaleza jurídica, ajena y distinta, por lo mismo, a la de la rama ejecutiva del poder público (C.P. arts. 113, 120 y 258 a 266)".

12 De acuerdo con el código electoral, el voto se manifiesta mediante el uso de papeletas de votación en las elecciones para corporaciones públicas y de tarjetas electorales para la elección del Presidente de la República, de conformidad con los artículos 123 y 124 respectivamente. Según el procedimiento establecido en el artículo 114, para hacer efectivo el voto se le exige al ciudadano la cédula de ciudadanía para verificar su identidad y buscar el número de la cédula en la lista de sufragantes. Si el ciudadano se encuentra en la lista, se le permite depositar el voto y se lleva a cabo el registro de que el ciudadano ha votado. Para la elección del Presidente de la República, identificado el votante, se le entrega la tarjeta o tarjetas electorales con el sello del jurado de votación en el dorso de la tarjeta. Posteriormente el elector se dirige al cubículo y registra su voto en el espacio que identifique al partido o agrupación política de su preferencia, o en el lugar previsto para votar en blanco. De igual forma, el artículo 116 permite votar en el exterior para Presidente de la República. Por su parte, la Constitución de 1991 en el artículo 40 consagra distintas manifestaciones por medio de las cuales se hace efectivo el derecho al voto, señalando que todo ciudadano puede elegir, ser elegido y tomar parte en elecciones, plebiscitos, referendos, consultas populares y otras formas de participación democrática. También, en el artículo 258 se establece que para el ejercicio del derecho al voto se pueden emplear tarjetas 
las mismas garantías y es deber de Estado proteger su ejercicio y la voluntad ciudadana manifestada en él.

La intención del constituyente en las reformas de 1991, 2003 y 2009 no ha sido establecer una única y exclusiva forma de ejercer el derecho al voto. Por el contrario, ha dejado un amplio margen de actuación para que legislador determine los tipos y formas de ejercer el voto, lo que permite la coexistencia de métodos tradicionales y la incorporación de sistemas electrónicos. Ahora bien, ha establecido asimismo las garantías que deben ofrecer todas las modalidades de votación, entre las que se incluye el voto electrónico, como las de ser secreto, libre en su ejercicio y sin coacción, y la de permitir la plena identificación del elector. La implementación de medios electrónicos debe privilegiarse, siempre y cuando con ello se cumplan con las anteriores garantías, pudiendo el legislador establecer plazos de ejecución al Gobierno nacional para el cumplimiento de dichas medidas ${ }^{13}$.

Una vez expuestos el voto, las garantías y sus características, corresponde exponer el marco normativo del voto electrónico.

\section{PRECISIONES SOBRE EL CONCEPTO Y CATEGORÍAS \\ DEL VOTO ELECTRÓNICO}

Desde un punto de vista jurídico y haciendo referencia a los procesos electorales, el voto electrónico puede ser definido como "el conjunto de acciones realizadas por la autoridad electoral, el elector y los funcionarios de casilla destinados a emitir su sufragio, efectuar el cómputo de la votación y transmitir los resultados electorales a través de medios informáticos" ${ }^{14}$. Asimismo, el voto electrónico puede clasificarse en dos categorías según la presencia del elector en centros o lugares establecidos de votación, esto es, voto presencial o voto remoto.

El primero de estos consiste en que el elector debe acudir a un lugar o puesto de votación para "ejercer su sufragio apoyado en la tecnología informática

electorales numeradas e impresas en papel que ofrezca seguridad, así como da la posibilidad de implementar el voto electrónico para lograr agilidad y transparencia en todas las votaciones.

13 En este sentido se pronunció la Corte Constitucional en la sentencia C-490 de 2011, fundamento n. ${ }^{\circ}$ 127: "Como se observa, el constituyente no optó por un mecanismo en particular para recepcionar el voto, destacó sí, que este debe ser secreto y libre de coacción, dejando abierta, de manera explícita, la posibilidad del uso de medios electrónicos e informáticos, siempre y cuando otorguen más y mejores garantías para el libre ejercicio del sufragio. [...] La jurisprudencia de esta Corporación señaló que es razonable la introducción de nuevos medios para agilizar y dar transparencia en todas las votaciones. Así mismo, recalcó que es posible que se adopten mecanismos electrónicos para ejercer el derecho al voto siempre que estén orientados a la realización plena del derecho al sufragio. Para tal efecto, el Congreso puede disponer la implementación de esos mecanismos, incluso cuando ello obliga indirectamente al Gobierno a incluir nuevos rubros en el presupuesto nacional, siempre y cuando los plazos establecidos sean razonables".

14 Romero Flores, R. y Téllez Valdés, J. A. Voto electrónico, derecho y otras implicaciones. México: Universidad Nacional Autónoma de México, 2010, 8. 
(urnas electrónicas), aunque de manera general la transmisión o concentración de los resultados por vía electrónica finalmente recae en disciplinas como la telemática, pero en esencia se trata de actos directos del elector frente a urnas electrónicas y funcionarios electorales" ${ }^{15}$. Dentro de esta categoría de voto electrónico pueden identificarse los siguientes dispositivos ${ }^{16}$ :

1. Las computadoras, ordenadores de voto o máquinas de votación: son instaladas en las mesas de votación y reemplazan el uso de los materiales tradicionales como las urnas, las papeletas y las cabinas. La máquina presenta al elector las diferentes opciones para su elección (candidatos, listas, respuestas en los referendos) y éste elige ya sea pulsando un botón, introduciendo un código o tocando directamente la pantalla de la máquina.

2. Los escáneres: se trata de sistemas de reconocimiento óptico para la lectura de papeletas y recuento de votos. Se usan papeletas para expresar la opción escogida y el elector o el personal de la mesa, coloca la papeleta en el escáner para finalizar el proceso de votación.

3. Bolígrafo o lápiz digital: mediante este método los electores utilizan un lápiz digital para marcar una o varias casillas en una papeleta. Las papeletas son impresas en un papel especial que permite al lápiz digital detectarlas mediante una cámara integrada al mismo. Gracias a ello, los registros del lápiz van memorizando las opciones marcadas por los electores.

4. Los kioscos: se trata de terminales conectadas a una computadora central o servidor. Se instalan en las mesas electorales y los dispositivos se encargan de recibir los votos y gestionar las listas y firmas de los electores.

5. Las unidades electrónicas de votación: se trata de cajas provistas de teclados numéricos, mediante las cuales los electores expresan sus opciones introduciendo un código que se transmite a una computadora central.

Por su parte el voto electrónico remoto implica "directamente el uso de la telemática para la emisión del sufragio y la concentración de los cómputos electorales, sin que necesariamente medie la presencia física de los ciudadanos" ${ }^{17}$. Dentro de esta categoría pueden distinguirse 3 clases de mecanismos de votación ${ }^{18}$ :

1. El voto mediante teléfono, fijo o móvil: en el caso del teléfono fijo, el elector debe llamar a una línea especial establecida para las elecciones, procediendo a identificarse y a autentificar su identidad con una contraseña recibida previamente por correo, luego de lo cual puede manifestar su intención de voto. En el caso de los teléfonos móviles el procedimiento es parecido,

15 Ibíd., 11.

16 Enguehard, Сh. Los dispositivos de voto electrónico "verificables”. En Guglielmi, G. J. e Ihl, O. (eds.), El voto electrónico. Madrid: Centre de Droit Public Comparé, Université Panthéon-Assas, 2017, 256-257.

17 RoMero Flores y Téllez VAldÉs. Voto electrónico, derecho y otras implicaciones, cit., 11.

18 Enguehard. Los dispositivos de voto electrónico "verificables", cit., 256-257. 
con excepción de que el voto se expresa mediante el envío de códigos por SMS (Short Message Service, por sus siglas en inglés).

2. El voto por internet: el elector, desde cualquier lugar con acceso a internet, procede a conectarse al sitio oficial de las elecciones y emitir el voto.

3. El voto por correspondencia híbrido: el elector marca sus opciones en una tarjeta que cuenta con un identificador o código de barras. Estas tarjetas son enviadas por correspondencia en sobre cerrado una mesa electoral centralizadora que procede a realizar la lectura de las tarjetas mediante un escáner.

Una clasificación adicional, propuesta por Barrat i Esteve, es la que distingue al voto electrónico según se adelante en un entorno controlado o no controlado. Los entornos controlados son los lugares especialmente dispuestos para la votación, en los cuales personas designadas de manera oficial se encargan de monitorear el procedimiento de votación ${ }^{19}$. Por su parte, los entornos no controlados carecen de dicha posibilidad de vigilancia e implican deficiencias en la identificación del votante y la posibilidad de coerción en el momento de expresar el voto ${ }^{20}$.

Una vez expuestas las precisiones conceptuales sobre el voto electrónico y los distintos mecanismos a través de los cuales se efectúa, se procede a exponer el marco normativo y el desarrollo jurisprudencial que ha tenido la implementación del voto electrónico en Colombia.

\section{MARCO NORMATIVO Y JURISPRUDENCIAL DEL VOTO ELECTRÓNICO EN COLOMBIA}

Bajo la vigencia de la Constitución de 1991 se han presentado varios proyectos de ley con el propósito de introducir el voto electrónico en los procesos electorales, pero tan solo tres de esos proyectos se han convertido en ley de la República. De otra parte, en varios proyectos de reforma constitucional se ha incluido la implementación de los sistemas electrónicos de votación.

La implementación del voto electrónico en Colombia inicia con el Acto Legislativo 01 de 2003, mediante el cual se modificó el artículo 258 superior. Con esta reforma la implementación de los sistemas electrónicos de votación quedó como una acción discrecional del gobierno y del legislador, pues en el parágrafo segundo del citado artículo se estableció que "podrá implementarse" el voto electrónico para buscar dos objetivos: agilidad y transparencia en las votaciones ${ }^{21}$. Sin embargo, el precepto constitucional no determina ni

19 Ibíd., 279.

20 Romero Flores y Téllez Valdés. Voto electrónico, derecho y otras implicaciones, cit., 11.

21 En cuanto a la garantía de la transparencia en las elecciones, el legislador ha establecido distintos tipos penales en el ordenamiento jurídico colombiano para sancionar las conductas que atentan contra el debate electoral. Dentro de ellos se encuentran los siguientes: (i) perturbación de certamen democrático (art. 39 de la Ley 1142 de 2007, que reformó el art. 386 del Código Penal); (ii) constreñimiento al sufragante (art. 387 del Código Penal); (iii) fraude al sufragante 
establece los elementos para delimitar el concepto de voto electrónico, solo menciona la posibilidad de la utilización de medios electrónicos o informáticos para su ejercicio.

En el marco legal colombiano se desarrolló el mandato de implementación del voto electrónico en el año 2004, con la Ley $892^{[22]}$. En esta ley se definió el voto electrónico, los requisitos mínimos con que debe contar la puesta en marcha de la votación electrónica y se estableció un plazo máximo de cinco años para su real implementación y utilización en las contiendas electorales. De acuerdo con el artículo 1. ${ }^{\circ}$ de la ley, el mecanismo de voto electrónico es aquel que sustituye las tarjetas electorales por terminales electrónicas que permitan identificar con claridad y precisión a todas las organizaciones políticas. Los puestos de votación y las urnas serán reemplazados por registros de bases de datos que contarán con los siguientes elementos: reconocimiento del votante, interfaz para la escogencia electoral y comunicación con la central de control. También se dispone que el sistema debe asegurar la aceptación de los tres tipos de cédulas existentes ${ }^{23}$.

De igual modo, el mecanismo debe incluir la lectura automática del documento de identidad, la captura de la huella dactiloscópica u otros métodos de identificación idóneos que validen y garanticen la identidad de la persona en el momento del sufragio. El artículo $1 .^{\circ}$ señala que los electores pueden obtener el certificado electoral a través de una página web determinada por la Registraduría Nacional en la cual se publicarán las cédulas que efectivamente sufragaron. Por último, se establece que la Registraduría puede determinar mecanismos adicionales para evitar la suplantación de personas en el momento

(art. 388 del Código Penal); (iv) fraude a inscripción de cédulas (art. 389 del Código Penal); (v) corrupción al sufragante (art. 390 del Código Penal); (vi) voto fraudulento (art. 391 del Código Penal); (vii) favorecimiento al voto fraudulento (art. 392 del Código Penal); (viii) mora en la entrega de documentos relacionados con una elección (art. 393 del Código Penal); (ix) alteración de resultados electorales (art. 394 del Código Penal); (x) ocultamiento, retención y posesión ilícita de cédula (art. 395 del Código Penal); (xi) denegación de inscripción (art. 396 del Código Penal); (xii) financiación de campañas electorales con fuentes prohibidas (art. 396 A del Código Penal); (xiii) violación de los topes o límites de gastos en las campañas electorales (art. 396 B del Código Penal); (xiv) omisión de información del aportante (art. 396 B del Código Penal).

22 Proyecto "por el cual se establece el voto electrónico" (Proyecto 081 de 2002 - Senado y 228 de 2003 - Cámara de Representantes).

23 A partir de lo establecido en el artículo 1. . de la Ley 757 de 2002, los colombianos debían renovar la cédula de ciudadanía (pues en ese momento había tres tipos de cédula con características diferentes) y la intención de la ley era unificar el documento de identidad, lo que permitiría la modernización de los procesos electorales. Dicho artículo establecía: "Atendiendo el estado de desarrollo del proceso de modernización tecnológico que adelanta la Registraduría Nacional del Estado Civil, previa consulta con el Departamento Nacional de Planeación, el Ministerio de Hacienda y Crédito Público y en concordancia a la sentencia de la Corte Constitucional C-511-99 del 14 de julio de 1999, precisará el término para que el ciudadano renueve su cédula de ciudadanía, el cual no podrá ir más allá del $1 .^{\circ}$ de enero de 2006 ”. Este plazo fue prorrogado hasta el $1 .^{\circ}$ de enero de 2010 por la Ley 999 de 2005. 
de votar. En este sentido, el voto electrónico será un mecanismo no solo para la votación misma, sino también para la inscripción de cédulas de ciudadanía.

El uso de las nuevas tecnologías de la información en los procesos electorales impone la obligación al Estado/organización electoral de tener en cuenta a las personas en situaciones especiales de discapacidad, para que invidentes o personas con cualquier otra situación que pueda dificultar el ejercicio del derecho al sufragio puedan hacer uso de este mecanismo de votación ${ }^{24}$. En el texto original del proyecto de ley la definición de voto electrónico era sencilla pero ambiciosa, pues con ella se pretendía que las personas pudieran ejercer el derecho al voto de manera remota. El texto del proyecto de ley establecía: "Se entenderá por voto electrónico: El sistema de votación que permite a los ciudadanos realizar el sufragio desde cualquier sitio en que se encuentren sin necesidad de acercarse a puestos de votación" 25 .

Sin embargo, en la Ley 892 de 2004 el voto electrónico es definido en función del uso de de modalidades automatizadas de votación, dejando la puerta abierta para la implementación de varias formas de votación; dentro de las que se incluyen la urna electrónica con lectura automatizada de tarjetas electrónicas, la votación a través de medio electrónico autónomo, y la votación electrónica en red. En el artículo 2. ${ }^{\circ}$ de la Ley 892 se extiende el mecanismo de votación electrónica a los ciudadanos colombianos residentes en el exterior. Dicha ley adopta algunas previsiones en orden a su implantación y contiene medidas especiales de protección para las personas con capacidades especiales y para los colombianos residentes en el exterior.

Uno de los requisitos para la implementación del voto es la disposición del rubro específico dentro de la Ley de Presupuesto General de la Nación. Esto es una ley de iniciativa del Gobierno; sin embargo, en la Ley 892 se establece que el inicio de los planes piloto de voto electrónico e inscripción se hará según la disponibilidad de los recursos estatales que dispongan las autoridades respectivas, ignorando la asignación del Presupuesto General ${ }^{26}$.

24 En cuanto a los ciudadanos invidentes o con discapacidades visuales ha establecido la Corte Constitucional en sentencia T-473 de 2003 que la Registraduría debe elaborar tarjetas braille que les faciliten su derecho al voto, las cuales les serán entregadas en el momento de presentarse en los puestos de votación con la respectiva cédula de ciudadanía.

25 Proyecto n. ${ }^{\circ} 081$ de 2002 - Senado, Gaceta del Congreso n. ${ }^{\circ} 395$ de 2002 y 430 de 2002, disponible en: www.secretariasenado.gov.co/gacetadelcongreso.htm (Consultado el 17 de mayo de 2018)

$26 \mathrm{Al}$ respecto, en la sentencia C-307 de 2004, fundamento jurídico n. ${ }^{\circ}$ 3.3.2.1. expuso: "En lo que respecta al gasto público el artículo tercero ordena dar inicio a los planes pilotos de votación con el nuevo sistema y, luego, implementar el nuevo mecanismo electrónico. Si bien lo ordenado no corresponde a los casos en los cuales la Constitución explícitamente requiere la iniciativa exclusiva del Gobierno, tampoco alude de manera específica a la inclusión de partidas en el presupuesto para financiar la aplicación del mecanismo electrónico de votación e inscripción para los colombianos. Es claro que la implementación del nuevo mecanismo y la puesta en marcha de los planes piloto sólo puede hacerse mediante gasto público, en la magnitud que finalmente determinen las autoridades competentes". 
El proyecto de ley estatutaria que se convertiría en la Ley 892 fue objeto de revisión previa por parte de la Corte Constitucional en la sentencia C-307 de 2004. En esta oportunidad la Corte manifestó que esta ley constituía una forma de protección de los derechos políticos, así como el cumplimiento del mandato de fortalecimiento de la democracia participativa, en el entendido de que permitía ampliar los canales de participación en los asuntos públicos. Otra de las cuestiones expuestas por la Corte en la sentencia es que las autoridades electorales cuentan con competencias residuales de reglamentación de la Ley 892 , en relación con los aspectos técnicos y operativos. La Corte concluye afirmando que no hay atribución general de competencia a la organización electoral para la reglamentación de los mecanismos electorales, por lo que no puede desplazar a la potestad reglamentaria en cabeza del Presidente de la República.

En el año 2008, por medio de la Ley 1227, se estableció que las instituciones educativas públicas y privadas deben permitir el uso de sus instalaciones físicas para el desarrollo de la jornada electoral, así como poner a disposición el personal que la organización electoral considere necesario para la operación del sistema electoral. De igual forma, se dispuso que los directores de las instituciones educativas pondrán a disposición las instalaciones de la institución educativa que consideren adecuadas, teniendo en cuenta los siguientes criterios:

1. Acceso a acometidas telefónicas.

2. Acceso a comunicación telefónica y/o vía módem.

3 . Acceso a parqueaderos para votantes.

Por otro lado, el artículo 39 de la Ley 1475 de 2011 dispuso que, con el fin de garantizar la agilidad y transparencia en las votaciones, la organización electoral implementaría el voto electrónico. Señalando también que el sistema que se adopte deberá permitir la identificación del elector con la cédula vigente o mediante la utilización de medios tecnológicos y/o sistemas de identificación biométricos, que hagan posible la plena identificación del elector. Por otro lado, se impuso el deber, en cabeza de la Registraduría Nacional, de implementar la identificación biométrica de los electores.

La Ley 1475 de 2011 estableció un sistema de implementación gradual y un límite máximo que iba hasta las elecciones para Congreso de 2014, lo cual era razonable para efectos de las decisiones que debía adoptar el Gobierno en materia de inclusión de rubros presupuestales.

En cuanto a la constitucionalidad de los artículos 39 y 40 de la Ley 1475 de 2011, la Corte manifestó en la sentencia C-490 de 2011 que el constituyente no optó por un mecanismo en particular para recepcionar el voto, pero destacó que debe ser secreto y libre de coacción, dejando abierta, de manera explícita, la posibilidad del uso de medios electrónicos e informáticos, siempre y cuando otorguen más y mejores garantías para el libre ejercicio del sufragio. Para tal efecto, el Congreso puede disponer la implementación de 
esos mecanismos, incluso cuando ello obligue indirectamente al Gobierno a incluir nuevos rubros en el presupuesto nacional, siempre y cuando los plazos establecidos sean razonables.

La Corte declaró la exequibilidad del artículo 39 de la Ley 1475 de 2011, por considerar que la posibilidad de implementar el voto electrónico está admitida de manera explícita por la Constitución, a condición de que en su ejercicio se respeten los atributos esenciales del derecho al sufragio, fundamentalmente su carácter secreto, libre de coacción e igualitario, y de que suministre garantías de transparencia y efectividad.

Esta corporación manifestó que el mandato de implementación de sistemas de identificación biométrica, dirigido a la autoridad electoral, tampoco contraviene la Constitución, toda vez que se orienta a fortalecer el procedimiento electoral mediante la introducción de mecanismos que permitan mayor seguridad y fiabilidad en los sistemas de identificación de los electores, y a rodear de mayor transparencia y eficacia los procesos de votación y escrutinio. Se trata de una estrategia operativa que en abstracto no ofrece reparos de constitucionalidad, pero que en su configuración, implementación y aplicación exige la preservación de la dignidad, la autonomía y la libertad del elector. A continuación se expone el estado actual de la implementación del voto electrónico en Colombia.

\section{ESTADO DE LA IMPLEMENTACIÓN DEL VOTO ELECTRÓNICO EN COLOMBIA}

Para poder evaluar el estado de la implementación del voto electrónico en Colombia resulta necesario hacer referencia y tener en cuenta los estándares que las organizaciones internacionales han establecido para medir la efectividad de los mecanismos de gobierno digital y, dentro de ellos, aquellas medidas que garantizan y amplían la participación ciudadana. De igual forma, es de utilidad conocer las experiencias comparadas en materia de voto electrónico para analizar los diversos contextos y determinar si los casos exitosos pueden servir como punto de referencia para Colombia. Posterior a ello, se exponen las etapas y los retos para la implementación del voto electrónico en Colombia y su estado actual.

\subsection{Algunos estándares internacionales sobre mecanismos de gobierno y participación digital}

La OCDE ha elaborado recomendaciones ${ }^{27}$ para la construcción de estrategias de implementación del gobierno digital, cuyo objeto es apoyar el desarrollo y la puesta en marcha de medidas que permitan fortalecer la relación de los

27 Recommendation of the Council on Digital Government Strategies, Adopted by the 
gobiernos y sus ciudadanos; reconociendo asimismo que las tecnologías de la información y de las comunicaciones pueden servir como apoyo para mejorar la eficiencia de las políticas públicas y contribuir a crear gobiernos más transparentes y garantizar la participación ciudadana. En particular, se recomienda que los gobiernos implementen estrategias de gobierno electrónico que:

1.Permitan garantizar la transparencia y la inclusión a las operaciones gubernamentales mediante la adopción de procesos incluyentes, accesibilidad y transparencia dentro de los objetivos de los planes de los gobiernos para la implementación de medidas de gobierno digital; actualizando las regulaciones actuales en virtud del reconocimiento del contexto actual establecido por los avances tecnológicos; y tomando medidas para reducir la brecha digital y evitar nuevas formas o manifestaciones de la misma.

2. Faciliten la participación de la ciudadanía en la elaboración de políticas públicas y el diseño y prestación de los servicios públicos.

3. Creen una cultura de manejo de datos e información digital en el sector público.

4. Manejen los riesgos de seguridad digital y violación a la privacidad, incluyendo la adopción de medidas efectivas y apropiadas para incrementar la confianza en los gobiernos.

La misma organización, en los talleres sobre indicadores de gobierno digi$\mathrm{tal}^{28}$, estableció que los mismos se elaboraron para medir el progreso de los países en la implementación de las recomendaciones expuestas. También señaló que las directrices principales que rigen los indicadores de desarrollo del gobierno digital pueden agruparse como sigue:

1. Garantía de transparencia en la interacción con los usuarios/ciudadanos.

2. Aspectos organizacionales y de gobernabilidad, como coordinación y contribución de cada uno de los ministerios y/o agencias en la consecución de los planes o agendas gubernamentales de implementación de medidas de gobierno digital.

OECD Council on 15 July 2014. Disponible en: http://www.oecd.org/gov/digital-government/ Recommendation-digital-government-strategies.pdf (Consultado el 16 de mayo de 2018)

28 OECD Workshop on Digital Government Indicators, Designing New Digital Government Indicators: Assessing Countries' Efforts to Leverage Digital Technologies for Public Sector Productivity and Inclusive Governance, 2016. Disponible en: http://www.oecd.org/gov/digitalgovernment/Summary-Digital-Government-Indicators-6-September-2016.pdf (Consultado el 16 de mayo de 2018). 
3. Uso de bloques de edificios y cambios internos como:

- Penetración de sistemas Tic: grado de reutilización, uso compartido, interoperabilidad (de sistemas, datos, etc.).

- Uso/aceptación en la administración de habilitadores clave genéricos (técnico, legal, identificación electrónica, etc.) parte de la infraestructura digital (bloques de construcción y plataformas a los que puede suscribirse toda la administración).

- Uso de estándares.

- Esfuerzos de consolidación.

- Existencia y uso de bases de datos/registros nacionales (p. ej., catálogos completados en la Administración Pública y calidad de gestión de esas bases de datos).

- Aspectos financieros y estandarización de los gastos o skillsets (bolsillos existentes dentro de la administración).

También es importante tener en cuenta los estándares establecidos en la Unión Europea por el Comité de Ministros del Consejo de Europa en 2004 ${ }^{[29]}$. Estrictamente hablando, se trata de una recomendación que provee definiciones básicas y la referencia al cumplimiento de principios como los relativos a que ${ }^{30}$ :

1. Los procedimientos de voto electrónico deben respetar todos los principios y garantías democráticas, debiendo tratarse de mecanismos que provean la misma confianza y seguridad que los procedimientos de votación tradicionales.

2. Las relaciones entre los aspectos legales, operacionales y técnicos de la implementación de los procedimientos de voto electrónico deben ser consideradas en el momento de aplicar la recomendación.

3. Los Estados miembros deben revisar y modificar sus ordenamientos para que se encuentren acordes con la recomendación.

Por su parte, la Comisión Económica para América Latina y el Caribe (Cepal), en su documento sobre indicadores de gobierno electrónico ${ }^{31}$, ha establecido como objetivo el fortalecimiento de la participación ciudadana, medido con dos indicadores: (i) porcentaje de servicios públicos, procesos de gestión y mecanismos de participación ciudadana automatizados; y (ii) porcentaje de consultas a la ciudadanía a través de internet. Adicionalmente, ha definido un índice de medición de "e-participación” o participación ciudadana elec-

29 "Legal, Operational and Technical Standards for e-Voting", Recommendation Rec (2004) 11 (Rec) (Council of Europe, 2004) adopted by the Committee of the Ministers of the CoE in September 30, 2004.

30 Prandini, M. y Ramilli, M. En e-Service Journal. Vol. 8, n. ${ }^{\text {o 3 }, 2012,42-72 .}$

31 Disponible en: https://www.cepal.org/ilpes/noticias/paginas/0/40660/alejandra_naser_INDICADORES.pdf (Consultado el 16 de mayo de 2018). 
trónica, compuesto por tres indicadores: (i) el aumento de la información electrónica a los ciudadanos en la toma de decisiones; (ii) la mejora de los procedimientos de consulta electrónica de los procesos deliberativos y participativos; y (iii) el apoyo en la toma de decisiones electrónicas mediante el aumento de la incorporación de los ciudadanos en la toma de decisiones.

De la lectura de las recomendaciones e indicadores de las organizaciones internacionales en materia de gobierno digital y participación ciudadana a través de medios electrónicos, pueden establecerse elementos comunes que contribuyen a guiar el proceso de implementación del voto electrónico en Colombia y el seguimiento a sus condiciones de operabilidad en caso de ponerse en marcha. Estos elementos son:

1. Debe existir una garantía de transparencia en los procedimientos de votación y participación ciudadana a través de medios electrónicos.

2. Debe haber una inclusión creciente de la ciudadanía en la toma de decisiones mediante los mecanismos de participación automatizados.

3. Deben establecerse medidas para hacer frente a los riesgos de implementación de medios de participación digital, los cuales permitan dar confianza a la ciudadanía respecto de la transparencia y efectividad de los mecanismos.

4. En todos los casos deben respetarse los principios y garantías propios de la democracia, así como los derechos fundamentales de participación política y de participar en las decisiones que afecten a la ciudadanía.

Si bien es difícil realizar una medición de estos estándares y recomendaciones en Colombia, dada la ausencia de mecanismos de participación electrónicos y de votación que sean vinculantes, resulta fundamental tomarlos como base para su implementación en el futuro, así como de las estrategias que construya el gobierno para utilizar las tecnologías de la información y de las comunicaciones en la mejora de la gobernabilidad y las relaciones con la ciudadanía. A continuación se exponen diversas experiencias de implementación del voto electrónico en otros países, las cuales pueden servir como referencia para definir el estado en que se encuentra el caso colombiano.

\subsection{Una mirada comparativa del desarrollo del voto electrónico en otros países}

En este apartado se exponen varias de las experiencias de implementación del voto electrónico en América y Europa. El objeto de la exposición es realizar una comparación entre las experiencias foráneas y colombiana, para determinar qué aspectos de aquellas podrían funcionar en nuestro país 
y contribuir a guiar el proceso de implementación del voto electrónico en Colombia. En primer lugar se exponen las experiencias sobre voto electrónico en otros países de América Latina ${ }^{32}$, cuyos contextos son más parecidos al colombiano y dentro de las cuales pueden resaltarse las de Brasil, Venezuela, Paraguay, Argentina, Perú y México.

En el reporte del año 2011, "Automatización del proceso electoral”, del Observatorio del Voto-E en Latinoamérica, se señala que Brasil es el único país del continente que ha implementado de manera satisfactoria un sistema de votación electrónica. Según este reporte, desde 1996, año en el cual se empezó a utilizar el sistema de voto electrónico, 478,5 millones de personas han ejercido su derecho al sufragio por esta vía. Este número corresponde a la cantidad de personas que han votado por dicho medio en las elecciones de 1996 (33 millones), 1998 (75 millones), 2000 (109 millones), 2002 (126 millones) y 2010 (135.8 millones).

El Tribunal Superior Electoral de Brasil empezó a automatizar de manera gradual los diferentes procedimientos que hacen parte del ejercicio del voto y del sistema de escrutinio. En la actualidad se encuentra implementando un sistema de identificación de votantes que le permitiría a Brasil convertirse en el primer país del continente en automatizar todas las fases del procedimiento de votación. El sistema implementado es una modalidad de los sistemas de Registro Electrónico Directo (RED, o DRE en inglés), en los cuales el voto se registra directamente en el instrumento de votación ${ }^{33}$.

La implementación del voto electrónico en Brasil ha producido resultados positivos en la ciudadanía, entre los que destacan: se ha logrado que el $90 \%$ de la población sepa utilizar las urnas electrónicas, gracias a un proceso pedagógico exitoso; el aumento de la confianza ciudadana en los partidos políticos; la reducción del índice de abstención electoral; la reducción del fraude electoral; el bajo número de fallas técnicas en los sistemas, y una notable reducción en los costos del proceso electoral ${ }^{34}$.

Otro caso digno de mencionar es el de Venezuela, país que ha sido pionero en el uso de tecnologías para el ejercicio del derecho al sufragio. La implementación del voto electrónico inició con la Ley Orgánica de Sufragio y Participación Política de 1997. Las primeras pruebas piloto comenzaron en 1998 y se han realizado en todo el país. Actualmente, el sistema se encuentra totalmente automatizado.

$32 \mathrm{Al}$ respecto, véase el documento realizado por la MOE titulado Breve contexto voto electrónico en Colombia. Disponible en: https://moe.org.co/home/doc/moe_nacional/2012/ votoelectronico.pdf (Consultado el 16 de mayo de 2018).

33 Reyes González, G. F. La democracia en la era digital: el voto electrónico y por internet como refuerzo de la confiabilidad de los sistemas electorales modernos. Medellín: Diké, 2015, 201.

34 Ibíd., 203. 
En Paraguay se implementaron mecanismos de voto electrónico en las elecciones presidenciales de 2003 y 2006, casos en los cuales se reconoció la transparencia, eficacia y agilidad del proceso. Entre los factores que contribuyeron al éxito en la implementación de los mecanismos de voto electrónico se encuentran: la confianza ciudadana en las autoridades electorales; una amplia campaña de capacitación a la ciudadanía; el apoyo de la oEA y del Tribunal Supremo Electoral de Brasil, y la convicción del pueblo y las autoridades sobre la necesidad de implementar las tecnologías en los procesos electorales ${ }^{35}$. En 2008 se hizo un retorno al sistema tradicional de voto por no existir consenso entre los partidos políticos respecto de la conveniencia de mantener el sistema electrónico.

En Argentina, la provincia de Buenos Aires ha sido pionera en la implementación del voto electrónico, luego de la sanción de la Ley 13.082 en el año 2003. En esa oportunidad se eligió el sistema de votación RED (o DRE, por sus siglas en inglés). A partir de 2003 también se realizaron pruebas en las provincias de Chaco, Mendoza y Tierra del Fuego, y en 2014 se presentó un proyecto de ley con el objeto de utilizar las tecnologías de voto electrónico a nivel federal.

En Perú se usó el voto electrónico en las elecciones municipales y regionales de 2014. En esa oportunidad se implementaron mecanismos de voto electrónico en siete distritos, específicamente en relación con 43.672 electores y 186 mesas de votación ${ }^{36}$. Sin embargo, se presentaron fallas por la inadecuada capacitación de los técnicos y los electores, así como retrasos en la entrega de los resultados, los cuales se conocieron siete horas después del cierre de los puestos de votación.

En el caso de Chile se intentó implementar el voto electrónico mediante un proyecto de ley a raíz de la baja participación en las elecciones municipales de $1996^{[37]}$. Sin embargo, esta iniciativa no se materializó, principalmente por dos factores: 1 . El contenido de la agenda legislativa de reforma política, la cual se enfocó fue en la modificación del sistema de inscripción en las listas electorales y la revisión del sistema electoral binominal; y 2. El apego o respeto de los ciudadanos chilenos al sistema de votación mediante papel y lápi ${ }^{38}$. A la fecha, en Chile no se han implementado mecanismos de votación electrónica con carácter vinculante.

En México se implementó el voto electrónico con efectos vinculantes el 25 de septiembre de 2005, en Coahuila. Tras Coahuila, "el Distrito Federal y Jalisco han impulsado ya experiencias vinculantes y, a nivel federal, el propio

35 Ibíd., 211.

36 Ibíd., 214.

37 JARA, R. La introducción del voto electrónico en Chile. En GiLles e IhL (eds.), El voto electrónico, cit., 82.

38 Ibíd., 87. 
Instituto Federal Electoral dispone de un prototipo y sus estudios internos consideran factible ensayar estos mecanismos en unas próximas elecciones" ${ }^{\prime 39}$.

En cuanto a la experiencia europea, Estonia fue el primer país del mundo en implementar el voto electrónico por internet a nivel nacional. Un ejemplo de esto fueron las elecciones municipales de 2013, cuando el voto a través de internet estuvo disponible durante siete días, entre el 10 y 16 de octubre. El conteo de los votos fue llevado a cabo el 20 de octubre y los resultados entregados el mismo día. De acuerdo con los datos oficiales, 133.808 votos se produjeron por internet, lo que equivale al $21.2 \%$ de los votos totales ${ }^{40}$. Otro aspecto destacable del caso estonio es la existencia de las tarjetas de identidad nacionales (National ID Cards), las cuales son usadas por los votantes para acceder a los servidores de votación, autenticar su identidad y firmar las balotas de votación.

En Bélgica se implementó el voto electrónico hace más de un cuarto de siglo, en 1991. Se han probado al menos siete procedimientos de automatización electoral y la experiencia puede resumirse en cuatro períodos: (i) 1991-1994, con el uso del panel táctil importado de los Países Bajos; (ii) 1994-1998, con el uso del lápiz óptico; (iii) 1998-2004, mediante la lectura óptica; y (iv) de 2005 a la actualidad, periodo en que se ha generado mucha confusión por, entre otras razones, el bug informático ocurrido después del cierre de las elecciones del 25 de mayo de 2014, el cual trajo como consecuencia la anulación de 2.250 votos $^{41}$.

Por su parte, la legislación alemana prevé la posibilidad de uso de máquinas o aparatos para la realización de los procesos electorales. El artículo 35 de la ley electoral federal alemana establece que "para facilitar la votación y el recuento de los votos pueden utilizarse aparatos electorales en lugar de papeletas electorales y urnas"42. De lo anterior se desprenden dos conclusiones: 1. La primera hace referencia a que el legislador alemán usó la expresión "para facilitar", para señalar la posibilidad de utilizar métodos alternativos de votación distintos a las papeletas y los sobres; 2 . La segunda, a que no se trata de una obligación de implementación de estos métodos, sino de una posibilidad de usar o no los mecanismos de voto electrónico ${ }^{43}$.

A continuación se exponen las etapas y los retos para la implementación del voto electrónico en Colombia.

39 ReYes González. La democracia en la era digital, cit., 190.

40 Springall, D. et al. Security Analysis of the Estonian Internet Voting System. Ann Arbor: University of Michigan, 2.

41 Bourgaux, A-E. Entre Jimena y Quimera. La experiencia del voto electrónico en Bélgica. En Guglielmi e Ihl (eds.), El voto electrónico, cit., 95-101.

42 RiveIra, R. M. F. ¿Es inconstitucional el voto electrónico en Alemania? En BARRAT I EsTEVE y RIVEIRA, Derecho de sufragio y participación ciudadana a través de las nuevas tecnologías, cit., 194.

43 Ibíd. 


\subsection{Etapas y retos para la implementación del voto electrónico en Colombia}

\subsubsection{Etapas para la implementación del voto electrónico en Colombia}

Para la correcta implementación del voto electrónico en Colombia deben agotarse distintas etapas. Se trata de un proceso de implementación gradual que, dadas las condiciones particulares del país, requiere del cumplimiento de pasos previos como lo son los que a continuación se enuncian.

\subsubsection{Renovación de la cédula de ciudadanía}

La cédula de ciudadanía es la prueba idónea de la calidad de ciudadano en Colombia, y el artículo 99 de la Constitución dispone que esta última es un presupuesto esencial para el ejercicio de los derechos políticos. Estos, a su vez, se traducen en la facultad de los nacionales para elegir y ser elegidos, tomar parte en elecciones, plebiscitos, referendos, consultas populares, cabildos abiertos, revocatorias de mandatos, constituir partidos, movimientos y agrupaciones políticas, formar parte de ellos libremente y difundir sus ideas y programas, promover acciones de inconstitucionalidad en defensa de la integridad y supremacía de la Constitución, desempeñar cargos públicos, etc. (arts. 40, 99, 103, 107, 241 C.P.).

De acuerdo con la Corte Constitucional, la Constitución y la ley le han asignado a la cédula de ciudadanía tres funciones diferentes pero unidas por una finalidad común, cual es la de identificar a las personas, permitir el ejercicio de sus derechos civiles y asegurar la participación de los ciudadanos en la actividad política que propicia y estimula la democracia ${ }^{44}$.

En Colombia ha habido un lento y pausado cambio del documento de identidad. En el año 2002 había tres clases de documentos de identidad con diferentes características. La introducción de nuevas tecnologías y los cambios en el desarrollo de los procesos electorales condujeron a la necesidad de unificación del documento. Por medio de la Ley 757 de 2002 se impuso un proceso de renovación de la cédula de ciudadanía hasta el 31 de diciembre de 2006, término que se prorrogó hasta el 31 de diciembre de 2009 por medio de la Ley 999 de 2005.

\subsubsection{Implementación de la biometría}

La biometría es una tecnología de identificación que mide e identifica alguna característica morfológica que diferencia a una persona de otra. Las huellas dactilares son el elemento más común utilizado para realizar identificación

\footnotetext{
44 Al respecto véase la sentencia C-511 de 1999, consideración n. ${ }^{\circ} 2.1$.
} 
biométrica. La biometría que usa la Registraduría se basa en el Automated Fingerprint Identification System (AFIS, por sus siglas en inglés). Se trata de una base de datos que sirve para verificar la identidad de una persona mediante de las características de sus huellas dactilares.

Este software crea un modelo computarizado de la huella y permite, a través de múltiples comparaciones, individualizar a las personas dentro de la base de datos en la que se clasifican y almacenan los registros para poder efectuar los cotejos. El sistema AFIS es el pilar fundamental en la aplicabilidad de la biometría para la individualización de los ciudadanos.

En Colombia, la primera prueba piloto de implementación de la biometría en elecciones se realizó en las consultas de partidos políticos del 26 de octubre de 2008, en la que se instalaron 67 lectores biométricos, los cuales fueron distribuidos así: 22 en Bogotá y 15 en Cali, Medellín y Barranquilla, respectivamente, siendo esta la primera experiencia, con una aplicación aleatoria.

No obstante, la primera elección atípica en la que se empleó oficialmente la biometría con carácter vinculante para todos los electores fue la de alcalde municipal de Belén de los Andaquíes, en el departamento de Caquetá, celebrada el 22 de febrero de 2009. En esta ocasión los ciudadanos fueron identificados a través de dispositivos que determinaban su plena identidad, en un proceso que duraba alrededor de tres minutos. Este proceso fue aplicado en otras doce elecciones atípicas de alcalde durante ese año.

Para la elección de alcalde de San Carlos, Antioquia, celebrada el 7 de junio de 2009, la Registraduría realizó además la primera prueba de escrutinio electrónico. Así mismo, en Murillo, Tolima, el 6 de junio de 2009, se intentó por primera vez utilizar dispositivos de identificación dactilar inalámbricos, y por segunda vez se hizo en los comicios adelantados el 27 de mayo de 2012 en el municipio de Cota, Cundinamarca.

La identificación dactilar o biometría se continuó aplicando en las elecciones atípicas desarrolladas entre los años 2011, 2012 y 2013, e hizo parte de las medidas adoptadas por la Registraduría para garantizar la transparencia en los comicios de gobernador llevados a cabo en los departamentos de Arauca y Amazonas en el año 2009, y en Caquetá y Bolívar en el año 2010, en donde además se desarrolló el primer plan piloto de voto electrónico.

Luego de las elecciones de autoridades locales celebradas el 30 de octubre de 2011, la Registraduría ha organizado 32 elecciones atípicas de alcaldes y gobernadores con el uso de herramientas biométricas inalámbricas, validando plenamente la identidad de los ciudadanos que acudieron a las urnas; en muchas de ellas se ha identificado al $100 \%$ de los sufragantes.

La biometría no ha sido de exclusiva aplicación en elecciones atípicas. Para las consultas de partidos realizadas el 27 de septiembre de 2009 se instalaron dispositivos de identificación del votante en los puestos de votación de Marly y la Plaza de Bolívar en Bogotá. Así mismo, el 30 de octubre de 2011 se aplicó por primera vez la identificación biométrica en elecciones ordinarias 
y se realizó el mayor despliegue de biometría en la historia electoral del país: tres millones de ciudadanos, es decir alrededor del 10\% del censo electoral, fueron identificados con herramientas biométricas ${ }^{45}$. Con la experiencia adquirida, la Registraduría ha logrado reducir el tiempo que tarda el cotejo dactilar, que hace cuatro años tomaba tres minutos y ahora tarda de dos a tres segundos, evitando congestiones en el ingreso de los puestos de votación.

Entre marzo y diciembre de 2013, en desarrollo de las elecciones para Congreso de la República y Presidente de la República del año 2014, mediante la captura de las huellas y la obtención de la información de los ciudadanos se dio la transición del papel a un formato automatizado de inscripción de cédulas. Los datos recopilados se confrontaron con el Archivo Nacional de Identificación, verificando la coincidencia de nombres y apellidos, así como la habilitación de los puestos de votación de acuerdo con la residencia declarada por los ciudadanos en los actos de inscripción. Este procedimiento se adelantó en las sedes de la Registraduría en 1.102 municipios, y también se llevó a cabo en diciembre de 2013 en 10.500 puestos de votación ubicados en 160 ciudades zonificadas.

Dicho procedimiento trajo como beneficios: evitar la pérdida y destrucción de documentos, evitar el proceso de digitación manual y el margen de error humanos, y contar con una base de datos de inscritos confiable. En los procesos electorales se utilizan lectores ópticos de huella que captan las impresiones dactilares presentes en las bases de datos de la Registraduría, lo cual permite conocer no solo la identidad de los votantes sino también su puesto de votación y si se encuentran habilitados para votar.

Según información proporcionada por la Registraduría, la implementación de la biometría ha permitido mejorar los procedimientos electorales, lo cual se ha visto reflejado en una mayor agilidad de los mismos. Asimismo, con ocasión del proceso de inscripción de cédulas, la biometría ha permitido tener mayores garantías de transparencia, siendo una herramienta fundamental para reducir la suplantación de electores e identificar a las personas llamadas a prestar el servicio de jurado de votación. Esta entidad también ha señalado que para las elecciones de autoridades locales en 2015, la biometría permitió tener una cobertura de 6.702 .998 ciudadanos que pudieron ser autenticados al ingresar a los puestos de votación.

\subsubsection{Pruebas piloto de voto electrónico}

Entre las experiencias que ha tenido el país en materia de voto electrónico se destacan las siguientes ${ }^{46}$ :

$45 \mathrm{Al}$ respecto véase: http://www.registraduria.gov.co/IMG/pdf/cuadro-elec-biometria.pdf (Consultado el 16 de mayo de 2018).

46 Véase el Documento de Trabajo para la Modernización de la Gestión Electoral, Prue- 
- 2006: elección atípica de alcalde de San José, Caldas. Esta experiencia contó con un censo municipal de 4.300 ciudadanos aproximadamente para el momento de la elección. Se utilizó una máquina de votación de tecnología tipo vol (OMR), de lectura de tarjeta de votación por escáner. Luego de ejercer su derecho al sufragio con el procedimiento de tarjeta electoral en papel, el ciudadano fue invitado a participar en un ejercicio pedagógico no vinculante del proceso de marcación de tarjeta. El porcentaje de participación fue del 70\%, y no se realizó encuesta al finalizar el ejercicio.

- 2007: elección de autoridades locales. Prueba piloto en Bogotá, Pereira y San Andrés. Esta prueba fue realizada durante la etapa preelectoral (27 de octubre) de la elección de autoridades locales en 2007. En el plan piloto se implementó la emisión presencial del voto, en la cual se hace uso de máquinas y programas específicos no conectados a internet. En esta forma de emisión presencial del voto se tienen dos sistemas, el de lectura óptica (LOv, lectura óptica del voto) y el sistema de registro electrónico directo del voto (RED). Previo a la prueba piloto se realizaron capacitaciones al personal del SENA en cada ciudad que participó de la prueba. Debido a los objetivos de la prueba y su característica de votación no vinculante, el objetivo de análisis fue la evaluación del desempeño y de la reacción del ciudadano al uso de los medios de voto electrónico.

- 2008: consultas de partidos. Prueba del Sistema Inteligente de Asignación de Mesa, "Siamesa". "Siamesa" es un sistema electrónico compuesto por un datáfono que contiene el censo electoral del puesto de votación. Este sistema identifica automáticamente las mesas con menor número de votantes en el momento en que el ciudadano se acerca a votar y con base en esta información determina a qué mesa puede dirigirse.

- 2009: consultas de partidos. Se adelantó una prueba de pantalla táctil y tablero electrónico en los puestos de Marly y Plaza de Bolívar en Bogotá. Con ocasión de las consultas de precandidatos de los partidos y movimientos políticos, la Registraduría implementó el voto electrónico vinculante en dos puestos de votación de Bogotá ubicados en Marly y en la Plaza de Bolívar. Se utilizaron máquinas RDE “touch screen” con periférico de impresión y caída al box del comprobante de votación.

- 2010: elección atípica de gobernador de Bolívar. Se adelantó una prueba piloto de voto electrónico en los puestos de la Universidad de Cartagena y Mompox. El 24 de octubre de 2011 se realizó la elección para elegir al gobernador del departamento de Bolívar. Con el propósito de ambientar el procedimiento de

bas Piloto de Voto Electrónico 2006 a 2011, Resumen, elaborado por la Secretaría Técnica de la Registraduría Nacional del Estado Civil. Para consultar los aspectos para la prueba piloto de voto electrónico 2014, véase http://www.registraduria.gov.co/IMG/pdf/ASPECTOS_PARA_LA_PRUEBA_DE_VOto_ELECTRONICO_2014.pdf (Consultado el 17 de mayo de 2018). 
votación electrónica, se solicitó a las firmas INDRA, EDP, ADS y CPS la instalación de tres máquinas de votación electrónica en el puesto ubicado en la plaza de la Gobernación de Cartagena y una adicional en la plaza en el municipio de Mompox. La tecnología utilizada para este proceso pedagógico fue RDE con "smart card" y pantalla "touch screen".

- 2011: elección de autoridades locales. Se realizó una aplicación de identificación biométrica al 10\% del censo electoral. Cumpliendo con lo dispuesto por la Ley 1475 de 2011, la Registraduría contrató con la firma Unión Temporal Biometría-2011, para las elecciones de autoridades locales y gobernación del 30 de octubre de 2011, la implementación de pilotos de sistemas de autenticación biométrica de los electores en varios los municipios del país que representaban el $10 \%$ del censo electoral. El proceso comprendió la instalación de las estaciones de control biométrico con sus respectivos operadores, a fin de verificar la plena identidad de los jurados de votación y de los electores.

- 2013: consultas internas de partidos y movimientos políticos. Se instalaron 33 puestos de votación en los cuales se realizaron pruebas de voto electrónico en las consultas internas de partidos y movimientos políticos para las elecciones legislativas y presidenciales del año 2014.

- 2014: prueba piloto de voto electrónico. Se realizó una convocatoria a empresas nacionales e internacionales para participar en una prueba piloto de voto electrónico para el 31 de enero de 2014. Esta prueba se realizaría en 93 puestos de votación, con el fin de estudiar y analizar las diferentes tecnologías de urna electrónica con lectura automatizada de tarjetas electorales y votación a través de pantallas táctiles o "touch screen" con soporte impreso al ciudadano. La idea era realizar una elección de carácter plurinominal. A esta prueba se presentaron 16 empresas, pero no se llevó a cabo debido a que la comisión asesora para la implementación gradual del voto electrónico no llegó a un consenso respecto de lo que se requería para realizar dicha prueba.

Luego de presentar las etapas para la implementación del voto electrónico en Colombia, se procede a explicar cuáles son los retos a los que se enfrentan las autoridades electorales para poner en marcha estas políticas públicas.

\subsubsection{Retos para la implementación del voto electrónico}

La implementación del voto electrónico en Colombia ha tendido a generar posiciones divididas, desde quienes "consideran que este es el remedio que solucionará todos los males de los procesos de votación en el país, hasta quienes creen que traer el voto electrónico implicará también 'importar' los fraudes electrónicos que padecen otros países, que se perciben como más 
sofisticados y complejos que los fraudes manuales" ${ }^{47}$. A continuación se exponen los retos principales para la implementación del voto electrónico en Colombia.

\subsubsection{Modernización de los mecanismos de votación}

Tanto en Colombia como en el resto de América Latina, los electores y las organizaciones políticas señalan a los organismos electorales la necesidad de tener en cuenta tres aspectos fundamentales para la implementación de mecanismos de votación electrónica: "eficiencia en el servicio de votación; confianza en las entidades electorales, exentas de velos, atmósferas turbias y cualquier indicio que pueda delatar fraude o manipulación, y resultados inmediatos" ${ }^{48}$. Sin embargo, otro de los inconvenientes esgrimidos para justificar la imposibilidad de tecnificar los procesos electorales es que los recursos de los que disponen los Estados son muy limitados y que constantemente "se está haciendo mención a la necesidad de reducir los costos de los procesos electorales, lo que obliga a los organismos encargados a plantear soluciones que incluyen sistemas eficientes, amigables y de bajo costo" 49 .

Independientemente del mecanismo de votación electrónica seleccionado por el Estado, lo cierto es que en su fase inicial de implementación "el dispendio económico puede llegar a superar con creces el monto destinado a la gestión de los procesos de votación tradicionales" ${ }^{50}$. Si llegase a optarse por mecanismos de votación remota también se deben realizar gastos de mantenimiento, actualización y mejora del software de votación. En caso de que se opte por elegir urnas electrónicas o terminales de votación, deben realizarse gastos para la adquisición de las máquinas, la capacitación de los funcionarios, sus viáticos durante la jornada electoral, los costes de desplazamiento y la infraestructura de comunicaciones ${ }^{51}$.

$\mathrm{Al}$ respecto, el Grupo de Estudios de Gobierno y Asuntos Internos de la Dirección de Justicia y Seguridad del Departamento Nacional de Planeación, en el documento de trabajo titulado "Implicaciones de la adopción del voto electrónico en Colombia" 52 , realizó diversos comentarios respecto de la implementación de los mecanismos de voto electrónico en el país. En primer

47 SÁnchez Torres, C. A. Transparencia, modernización y voto electrónico en la Registraduría Nacional. En Araújo Oñate, R. Retos y tendencias del derecho electoral. Bogotá: Universidad del Rosario, 2014, 476.

48 Tuesta Soldevilla, F. El voto electrónico. En Zovatto, D. et al. Tratado de derecho electoral comparado de América Latina. México: Fondo de Cultura Económica, 2011, 959.

49 Ibíd.

50 Reniu Vilamala, J. M. Demasiados talones para un solo Aquiles. En Cotarelo, R. y Olmeda, J. A. (eds.), La democracia del siglo XXI: política, medios de comunicación, internet y redes sociales. Madrid: Centro de Estudios Políticos y Constitucionales, 2014, 92.

51 Ibíd.

52 Departamento Nacional de Planeación, DNP, Grupo de Estudios de Gobierno y Asuntos 
lugar, señaló que para la fecha de elaboración del documento los recursos de inversión de la Registraduría no permitían que el Estado colombiano entrara de inmediato en un proceso de adquisición de la tecnología necesaria para implementar el voto electrónico, lo que hacía necesario que el proceso de implementación fuese gradual, estableciendo partidas presupuestarias suficientes para llevarlo a cabo.

De igual forma, puso de presente la necesidad de implantar un sistema que permitiese evitar la manipulación fraudulenta de los resultados. Otra de las recomendaciones fue la de unificar la identificación de los ciudadanos por medio del proceso de recedulación, señalando que la posibilidad de constatar la identidad de todos los ciudadanos por métodos biométricos en las elecciones dependía de este factor. El documento también subrayó que la implementación del voto electrónico en la organización de las elecciones era viable, teniendo en cuenta las experiencias ya adquiridas en Brasil y Paraguay. En este sentido, se abría la posibilidad de organizar comicios en donde el manejo de la información electoral se hiciera a través de herramientas tecnológicas, con el fin de dar mayor transparencia a las jornadas de votación.

\subsubsection{Ausencia de voluntad política}

La modernización del sistema electoral es apenas uno de los retos que es preciso enfrentar para el mejoramiento integral del sistema electoral. A esto se suman el reto de garantizar la autonomía de la organización electoral, la creación de un verdadero tribunal para tales efectos, la garantía de participación y representación para todos los sectores de la sociedad colombiana, y el creciente abstencionismo electoral. De esta forma, la implementación de tecnologías para garantizar la transparencia y agilidad del proceso electoral se configura como una parte dentro de un todo que es el sistema electoral colombiano, entendido como las reglas establecidas que rigen los procesos electorales, el funcionamiento de las instituciones, la presentación de los candidatos, los métodos de votación y las directrices con base en las cuales deben adelantarse las campañas. Asimismo, los retos evidenciados para la implementación del voto electrónico deben ser analizados con los que tiene el funcionamiento del respectivo sistema electoral.

Desde finales del siglo xx se ha intentado crear y consolidar una autoridad electoral que garantice autonomía e independencia. Sin embargo, Colombia la organización electoral ha estado altamente politizada y las reformas que se han implementado no han contribuido a la consecución de dichos objetivos. Ejemplo de ello han sido las distintas propuestas presentadas por los partidos y movimientos políticos referentes a la consolidación de un modelo

Internos de la Dirección de Justicia y Seguridad. Implicaciones de la adopción del voto electrónico en Colombia, documento de trabajo, mayo de 2003. 
de justicia electoral en el país, como las propuestas que se presentaron ante la Asamblea Nacional Constituyente de 1991 para constitucionalizar la regulación de los órganos electorales y para el "establecimiento de una corte o tribunal electoral, de naturaleza judicial, a quien se le atribuía de manera definitiva la resolución de los conflictos que se presentaran en el marco de las elecciones" ${ }^{33}$. Sin embargo, el resultado se limitó a darle rango constitucional a la organización electoral, sin proceder a la creación de un tribunal o corte electoral.

En los antecedentes de la reforma constitucional de 2003 también se insistió en la necesidad de modificación integral del sistema electoral, así como de crear una corte o tribunal para tales efectos. Esta propuesta fue incluso aprobada en la primera vuelta del trámite de la reforma. Sin embargo, la proposición "no tuvo acogida por los legisladores en la segunda vuelta del trámite legislativo y terminó por aplazar nuevamente la reforma estructural al modelo de justicia electoral" ${ }^{54}$.

Por otro lado, el proyecto de Acto Legislativo n. ${ }^{\circ} 12$ de 2017 - Cámara, el cual ordenaba la reglamentación del uso de medios digitales para los mecanismos de participación ciudadana, fue archivado en cuarto debate en la plenaria del Senado ${ }^{55}$. Al propio tiempo, el Consejo de Estado no quiere perder la competencia que tiene respecto a la resolución de las acciones de nulidad electoral. Por tal razón, la propuesta de creación del tribunal electoral se eliminó, creando el Consejo Electoral y suprimiendo las funciones electorales que se le habían asignado.

Debe ponerse de presente que en la actualidad existe poca confianza en el modelo de democracia representativa establecido por la Constitución de 1991. Este modelo trae consigo una imposibilidad fáctica de representar los intereses de todos los sectores de la población que deben estar representados en los distintos cargos de elección popular. Esta falta de confianza en los órganos y funcionarios llamados a representar los intereses ciudadanos puede ser una de las causas del creciente abstencionismo en el país. En efecto, según la Encuesta de Cultura Política del DANE, ECP-2017, entre las instituciones o actores en que las personas de 18 años y más no confían se encuentran los partidos o movimientos políticos $(61,6 \%)$ y el Congreso de la República $(51,7 \%)$. Lo anterior guarda relación con las razones dadas para no participar de las elecciones, es decir: porque se considera que los políticos son

53 Vanegas Gil, P. P. Estudios de derecho electoral. Bogotá: Universidad Externado de Colombia, 2008, 181.

54 Ibíd., 88.

55 Gaceta n. $^{\circ} 1083$ de 2017. Ver: http://www.congresovisible.org/proyectos-de-ley/ppormedio-del-cual-se-adopta-una-reforma-politica-y-electoral-que-permita-la-apertura-democraticapara-la-construccion-de-una-paz-estable-y-duradera-reforma-politica-y-electoral/8863/\#tab=2 (Consultado el 16 de mayo de 2018). 
corruptos $(46,2 \%)$, porque los candidatos prometen y no cumplen $(44,6 \%)$ y por desinterés $(43,3 \%)$.

\subsubsection{Necesidad de capacitación ciudadana}

La brecha digital y la capacidad de la ciudadanía para el correcto uso de las tecnologías de la información y de la comunicación, en particular de las herramientas de voto electrónico, es fundamental para la correcta implementación de este. La brecha digital hace referencia a las desigualdades que existen para el acceso a internet con base en factores como los ingresos, la edad, el nivel de educación, la pertenencia a una raza o etnia específica, y la vida en el campo o la ciudad ${ }^{56}$. Se trata de un aspecto clave para obtener resultados positivos en la introducción de tecnología en los comicios. Por lo general, las personas con ingresos más altos por año, las personas jóvenes, los hogares en los que conviven los dos padres, y las personas con alta formación académica, tienen más probabilidades de tener acceso fácil a las tecnologías de la información y las comunicaciones como internet ${ }^{57}$. Por el contrario, las personas que se encuentra del lado contrario deben hacer un mayor esfuerzo para aprovechar de manera plena las opciones que ofrecen las tecnologías de la información y las comunicaciones.

En este sentido, otros de los retos para reducir la brecha digital y lograr la implementación de herramientas digitales en los comicios son la superación del analfabetismo y la capacitación en el uso de las tecnologías para mejorar el debate democrático. La implementación del voto electrónico no solo se enfrenta a los costos que trae consigo la compra e implementación de software y hardware adecuados, sino también a la capacitación de la población en el uso de estas herramientas. Si bien se ha ido reduciendo la brecha digital y se ha ampliado el acceso a medios electrónicos, una cosa es que cada vez más las personas utilicen la tecnología para efectos de ocio y comunicación, y otra que sea usada como instrumento democrático y de producción y acceso al conocimiento.

No basta con que mediante leyes o reformas se establezca un mandato de introducción de tecnología. Debe tenerse en cuenta también que una correcta implementación requiere de la elaboración de políticas públicas que tengan en cuenta el contexto que se vive en cada región del país. Si bien en las ciudades capitales esto puede no resultar tan problemático, debe recordarse que gran parte de la población vive aún en el campo o en municipios en los cuales el acceso a la tecnología no se encuentra tan difundido como en las ciudades. Si el objetivo de implementar el voto electrónico es el de

56 HiLl, E. Some Thoughts on e-Democracy as an Evolving Concept. En Journal of eGovernment. 1, 1, 2004, 27.

57 Ibíd. 
garantizar la agilidad y la transparencia en las elecciones, es fundamental que los electores se encuentren en capacidad de acceder sin problemas a los medios digitales para efectos de sufragar y consultar la información necesaria para ejercer su derecho en plenas condiciones y con todas las garantías que establece la Constitución.

De igual forma, el sistema de votación electrónica que vaya a implementarse debe presentarse al elector de una manera sencilla, de modo que este pueda ejercer su derecho al voto con agilidad ${ }^{58}$. También debe resultar de fácil uso para las personas en condición de discapacidad o con bajo nivel educativo ${ }^{59}$.

Adicionalmente, es importante que se dé una correcta capacitación a los jueces de votación ${ }^{60}$, quienes adquieren una responsabilidad importante dentro del proceso de implementación y correcto funcionamiento de los mecanismos de voto electrónico. Al respecto debe tenerse en cuenta lo sucedido en Estados Unidos en las elecciones del año 2000, cuando se presentaron problemas "por la poca efectividad que tuvo el entrenamiento, como lo dice el testimonio de una juez de mesa en Maryland, quien argumentó que las explicaciones fueron demasiado rápidas y que tuvo poco contacto previo con la máquina, generándose gran confusión durante la elección" ${ }^{61}$.

\subsubsection{Confianza ciudadana y observación electoral}

No es un secreto que entre los factores que contribuyen a la legitimidad de los gobiernos se encuentran los procesos electorales respecto de los cuales existe una confianza colectiva ${ }^{62}$. Esta legitimidad es fundamental para el funcionamiento de las democracias a largo plazo, ya que hace que los perdedores en los comicios respeten la victoria y las políticas que hayan de ser establecidas por los ganadores, incluso si se encuentran en desacuerdo, lo que sucede en la mayoría de los casos ${ }^{63}$. Puede afirmarse que existe confianza cuando se presenta la creencia de que serán respetados los resultados electorales y hay

58 ReYes GonZÁLEz. La democracia en la era digital, cit., 360.

59 Ibíd. Esta afirmación se encuentra en consonancia con lo establecido en el artículo $1 .^{\circ}$ de la Ley 892 de 2004 que dispone: "La Organización Electoral diseñará y señalará los mecanismos necesarios para que el voto electrónico se realice con la misma eficacia para los invidentes, discapacitados o cualquier otro ciudadano con impedimentos físicos".

60 "In general, poll workers must know how to use the systems at least as well as any voter would need to know, and they must know still more than that, because they will be the first line of assistance for voters who are confused about how the system works. Poll workers must know enough about the system in use to be able to recognize a problem that arises at a voting station, and then to take action to correct the problem". CELESTE, R. F. et al. Asking the Right Questions about Electronic Voting. National Academies Press, 2006, 101.

61 Ibíd., 361.

62 Álvarez, R. M. y Hall, T. E. Electronic Elections: The Perils and Promises of Digital Democracy. Princeton University Press, 2008, 134.

63 Celeste et al. Asking the Right Questions about Electronic Voting, cit., 29. 
garantías mínimas de transparencia en los comicios, de manera que la ciudadanía puede constatar que el proceso de votación y escrutinio se adelanta de conformidad con las reglas establecidas.

También es preciso tener en cuenta que el nivel de confianza dependerá del contexto, ya que las condiciones especiales de cada grupo social provocarán reacciones diferentes ante los mecanismos de votación electrónica y tendrán influencia en las distintas medidas que se adopten para garantizar la confianza ciudadana en el método implementado para el ejercicio del derecho al sufragio y la realización de los escrutinios. Así las cosas, mientras que "determinadas cautelas institucionales pueden considerarse como suficientes en un país, en otro pueden contemplarse de un modo distinto" ${ }^{64}$, por lo que el voto electrónico tendrá que adaptar su estructura a diferentes realidades; "los retos pendientes en un determinado sistema electoral, la polarización social, el grado de penetración de las nuevas tecnologías son [...] algunos de los factores que habrá que tener en cuenta" ${ }^{65}$.

Respecto del contexto estadounidense se han usado datos de las elecciones de 2004 para comparar el impacto de distintos sistemas de votación en la confianza de los electores, encontrando que aquellos que votaron mediante máquinas de voto electrónico tenían menos confianza en el procedimiento y los resultados que aquellos que lo hicieron a través del sistema tradicional de papel. Se ha podido establecer que los ciudadanos no confiaban en las máquinas, y que ello se debía posiblemente a las noticias negativas sobre la susceptibilidad de las votaciones electrónicas a las fallas y fraudes, teniendo en cuenta lo sucedido en las elecciones presidenciales del año $2000^{[66]}$.

Esta desconfianza deriva también de los malentendidos que se han presentado al intentar explicar la conveniencia de la implementación del voto electrónico, malentendidos que hacen énfasis en una presunta ausencia de controles en el momento de emitir el voto. Al respecto se ha esgrimido, como crítica para alimentar la desconfianza, la coacción que puede sufrir el votante al votar en un escenario en el que ninguna autoridad protege sus derechos. Ahora bien, aunque es verdad que la coacción al elector es un riesgo real, no es cierto que en todos los escenarios de votación electrónica exista ausencia de vigilancia o control, ya que "la práctica más habitual es la que aprovecha entornos controlados vinculados a los colegios electorales para la ubicación de urnas electrónicas" ${ }^{67}$.

64 JoRdi BARRAT I Esteve, J. Observación electoral y voto electrónico. En Revista Catalana de Derecho Público. N. ${ }^{\circ}$ 39, 2009, 8.

65 Ibíd.

66 Álvarez, R. M., Katz, G. y Pomares, J. The Impact of New Technologies on Voter Confidence in Latin America: Evidence from e-Voting Experiments in Argentina and Colombia. En Journal of Information Technology \& Politics. 2011, 201.

67 Reniu Vilamala. Demasiados talones para un solo Aquiles, cit., 83. 
En estos entornos controlados se opta generalmente por introducir recibos de papel expedidos en el momento de votar para que puedan ser verificados por los votantes. Pero lo anterior parece no ser suficiente, ya que también debe verificarse la correcta transmisión de los datos introducidos en las urnas electrónicas y su concordancia con los recibos expedidos a los votantes, proceso que "debería venir soportado por la posibilidad de realizar auditorías de cada una de las urnas electrónicas, por parte del personal competente técnicamente" 68 .

En el caso colombiano, como en la mayoría de los países de Latinoamérica, la transparencia en los procesos electorales es un elemento fundamental y la confianza en las autoridades electorales es relativamente baja ${ }^{69}$. Para la Misión de Observación Electoral, el gran reto de la implementación de tecnologías de información al sistema tiene que ver con la transparencia de las elecciones y la confianza del público en los resultados. Lo anterior, en atención a que "estas tecnologías limitan la posibilidad de que los partidos políticos o un ciudadano común verifiquen si las elecciones son auténticas o si ha habido vicios o fraudes"70. Para responder a este reto de transparencia y construir la confianza de la ciudadanía, el país debe garantizar unas condiciones mínimas para establecer el voto electrónico en todo el territorio nacional. Al respecto, la MOE realizó distintas recomendaciones que se resumen en tres aspectos:

\section{El respeto de los principios democráticos.}

2.El respeto de las garantías procesales, en especial de seguridad jurídica, igualdad ante la ley, equidad y debido proceso.

3. Mejoras en los aspectos operativos, haciendo referencia a la capacitación e información de manera simple para que todos los ciudadanos estén en capacidad de votar por medios electrónicos; la obligatoriedad de que los resultados únicamente puedan ser consultados finalizada la elección; y la gradualidad de implementación de las herramientas.

En este sentido, se ha dicho que la observación electoral se encuentra "estrechamente ligada tanto a la transparencia como a la supervisión real de los comicios, pero los sistemas electrónicos de votación pueden invalidar ambos

68 Ibíd., 99.

69 Álvarez, Katz y Pomares. The Impact of New Technologies on Voter Confidence in Latin America: Evidence from e-Voting Experiments, cit., 204.

70 Misión de Observación Electoral. Implementación del voto electrónico en Colombia Recomendaciones, octubre de 2014. Disponible en: http://moe.org.co/wp-content/uploads/2017/06/ Libro-Implementaci\%C3\%B3n-del-Voto-electr\%C3\%B3nico-en-Colombia.pdf (Consultado el 17 de mayo de 2018). 
elementos de manera frontal"71 . Ello es percibido de esta forma debido a que los eventos electrónicos tienen lugar en escenarios que no se encuentran sujetos a una capacidad de observación o seguimiento por medio del sentido de la vista, ya que se trata de procedimientos tecnológicos que no son pueden ser comprendidos por el observador promedio ${ }^{72}$. En este punto surge así otro elemento importante dentro del contexto de la confianza ciudadana, y es el referido a la comprensión de los sistemas de votación electrónica.

La comprensión de los procesos electorales, si bien es un elemento independiente, puede contribuir a generar confianza en los mecanismos de votación electrónica. Una ciudadanía que tenga un conocimiento mínimo del funcionamiento de los mecanismos de sufragio tendrá una mayor capacidad de aceptación de los mismos, lo cual va de la mano con la publicidad de estos medios y con la capacitación ciudadana que se adelante con ocasión de la implementación del voto electrónico. El miedo a lo desconocido y lo incomprendido puede provocar desconfianza, sobre todo si se trata de procedimientos tecnológicos que no pueden ser verificados con la simple observación. En el supuesto de un modelo de voto electrónico bien diseñado, con una correcta capacitación, la comprensión completa del proceso electoral generará confianza ${ }^{73}$ ciudadana, aunque también "es posible que esta segunda aparezca sin que haya realmente una comprensión tan exhaustiva e ilimitada" ${ }^{74}$.

\subsubsection{El voto electrónico y su relación con el abstencionismo electoral}

Otro de los aspectos importantes relacionados con la implementación de mecanismos de voto electrónico es el referente a que el uso de las tecnologías de la información y de las comunicaciones contribuye a reducir el abstencionismo y promueve la participación ciudadana. Se trata de "uno de los principales argumentos repetidos hasta la saciedad por los ciberoptimistas defensores a ultranza del voto electrónico: TICs = más y mejor participación"75, el cual no debe tomarse como una verdad absoluta ni comprobable en todos los casos. Es pertinente señalar que la participación ciudadana en el ámbito político y electoral "está condicionada por múltiples factores (por ejemplo, el desarrollo socioeconómico y la modernización; la estructura institucional o el contexto político; los recursos grupales y la movilización; las características socioeconómicas individuales; las actitudes políticas; la percepción de la

71 BarRat i Esteve. Observación electoral y voto electrónico, cit., 2.

72 OSCE/ODIHR. OSCE/ODIHR Discussion Paper in Preparation of Guidelines for the Observation of Electronic Voting. Varsovia: OSCE (Organización para la Seguridad y la Cooperación en Europa) / ODIHR (Office for Democratic Institutions and Human Rights), 2008, 2.

73 BARRAT I ESTEVE. Observación electoral y voto electrónico, cit., 7.

74 Ibíd.

75 Reniu Vilamala. Demasiados talones para un solo Aquiles, cit., 93. 
importancia del proceso electoral, etc.) entre los que la forma -tradicional o electrónica- de expresión del voto apenas tiene relevancia"76.

Así las cosas, no puede esperarse que la implementación del voto electrónico por sí misma contribuya a transformar la percepción ciudadana de los procesos electorales y a aumentar la participación. Sin embargo, puede observarse que en el caso brasilero se ha presentado un aumento de la participación ciudadana, a pesar de que el voto electrónico no sea el único factor determinante para ello. Si bien, a partir de la implementación del voto electrónico en Brasil, se han reducido los índices de abstención, a ello también han contribuido otros factores, como la capacitación ciudadana y la confianza de los ciudadanos y los partidos políticos en los resultados electorales y en el Tribunal Electoral.

Por otro lado, en casos como el español no se han obtenido los resultados esperados. La implementación del voto electrónico se han visto circunscrita exclusivamente a pruebas piloto y el resultado en términos participativos es bastante pobre. No solo "no se ha conseguido motivar a los ciudadanos para que tomaran parte en dichas iniciativas sino que, además, la ausencia de efectos vinculantes ha ido generando un poso de cansancio, frustración y desinterés que llegó a sus cotas máximas en la prueba piloto previa al referéndum sobre el tratado de la Unión Europea"77.

Una vez expuestos los retos para la implementación del voto electrónico en Colombia, se pasa a explicar el estado actual del voto electrónico en el país.

\subsection{Estado actual del voto electrónico en Colombia}

Si se compara con las experiencias internacionales expuestas, Colombia se encuentra muy atrás en materia de voto electrónico. Aún no ha sido posible implementar la tecnología para ejercicios electorales vinculantes, y todos los ejercicios de implementación del voto electrónico se han quedado como simples pruebas o pilotos. A pesar de lo anterior, los casos de Bélgica y Estonia pueden servir para estudiar la efectividad de los diversos mecanismos de votación electrónica disponibles y utilizados por estos Estados, para aprender de sus errores y aciertos.

En el caso de los países latinoamericanos existen patrones similares, debido al contexto socioeconómico y político. Tomando como referencia el caso de Brasil, una adecuada capacitación y proceso de acompañamiento pueden contribuir a aumentar la participación y la confianza en las instituciones. Adicionalmente, la experiencia de Perú permite vislumbrar que en Colombia también sería fundamental realizar una capacitación adecuada del personal técnico y operativo que acompañe la celebración de las elecciones.

76 Ibíd.

77 Ibíd. 
Por otro lado, comparando a Colombia con las experiencias de Chile y Paraguay -países que tienen un sistema de gobierno parecido y una similar descentralización administrativa- existen patrones semejantes, en el sentido de que la implementación del voto electrónico ha dependido exclusivamente de la voluntad de los partidos políticos, a pesar de que el ordenamiento jurídico autorice su implementación. En estos casos el principal obstáculo parece ser la agenda política, tanto de los gobiernos como de sus órganos legislativos, y al tratarse de la implementación de políticas públicas de gobierno digital, su ejecución seguirá sujeta a la importancia que los respectivos gobiernos le den.

A pesar de que en Colombia se han establecido diversos mandatos de implementación del voto electrónico, tanto por vía de reforma constitucional (Acto Legislativo 01 de 2003) como por vía de ley (Ley 892 de 2004 y Ley 1475 de 2011), a la fecha no ha sido posible implementar mecanismos digitales en los comicios nacionales. Si bien la Ley 1475 de 2011 estableció el mandato de dar aplicación a estos mecanismos para las elecciones de 2014, dichos términos no fueron cumplidos y la situación sigue pendiente de resolución.

Actualmente la utilización de medios electrónicos en las elecciones cobra mayor relevancia. El Acuerdo Final de Paz, suscrito entre el Gobierno Nacional y las FARC-EP, incluye entre las medidas para la promoción de la transparencia en los procesos electorales, contenidas en el punto 2.3.3.1 ${ }^{178]}$, el mandato de apoyar la implementación de los medios electrónicos. Sin embargo, a la fecha no se ha expedido ley alguna para implementar estas medidas, y, como ya se dijo, el proyecto de Acto Legislativo n. ${ }^{\circ} 12$ de 2017 - Cámara, el cual ordenaba la reglamentación del uso de medios digitales para los mecanismos de participación ciudadana, fue archivado en cuarto debate en la plenaria del Senado $^{79}$. Dentro del articulado de esta fallida reforma política se adicionaba otro parágrafo al artículo 258 de la Constitución que establecía un mandato de implementación del voto electrónico iniciando con los ciudadanos colombianos residentes en el exterior.

De haberse aprobado la reforma, serían ya tres mandatos de implementación del voto por medios electrónicos en el país (adicional a las leyes 892 de 2004 y 1475 de 2011), además de la posibilidad de implementación establecida por el Acto Legislativo 01 de 2003. En este sentido, se observa que a pesar de todos los intentos por institucionalizar y poner en marcha los mecanis-

78 Acuerdo Final de Paz, punto 2.3.3.1: "Medidas para la promoción de la transparencia en los procesos electorales: Con el objetivo de promover una mayor transparencia electoral, el Gobierno Nacional garantizará, junto con las autoridades competentes, la implementación de las siguientes medidas: [...] Apoyar la implementación de medios electrónicos en los procesos electorales, con garantías de transparencia".

79 Gaceta n. ${ }^{\circ} 1083$ de 2017. Disponible en: http://www.congresovisible.org/ proyectos-de-ley/ppor-medio-del-cual-se-adopta-una-reforma-politica-y-electoral-que-permita-la-apertura-democratica-para-la-construccion-de-una-paz-estable-y-duradera-reformapolitica-y-electoral/8863/\#tab=2 (Consultado el 16 de mayo de 2018). 
mos de sufragio a través de herramientas digitales, la voluntad política de las autoridades sigue teniendo un papel determinante en la implementación del voto electrónico.

Los altos costos que implica, la seguridad y la ausencia de decisiones de carácter administrativo por parte de la Registraduría han servido como barreras a la implementación de estos mecanismos de sufragio. Esta situación ya había sido puesta de presente por el DNP, al señalar en 2003 que "[1]os recursos de inversión con los que cuenta la Registraduría General del Estado Civil, no permiten que el Estado colombiano entre de inmediato en un proceso de compra de la tecnología necesaria para implementar el voto electrónico". A la fecha todas las pruebas de voto electrónico han sido de carácter "no vinculante", excepto la aplicación de la identificación biométrica y la prueba realizada en las consultas de partidos de 2009 y 2013. Sin embargo, se han producido otros avances en materia de inscripción de candidaturas, sorteo de los jurados de votación, y preconteo y escrutinio.

En las elecciones locales de 2015 la Registraduría creó un link en su sitio web para que los partidos, movimientos políticos y grupos significativos de ciudadanos generasen vía internet los formularios de inscripción de los candidatos. En cuanto a los sorteos de jurados de votación, la Registraduría ha implementado una solución tecnológica en la que se utiliza una plataforma web para realizar el sorteo de los jurados. Esta herramienta ha permitido superar las deficiencias detectadas en la designación de los jurados de votación durante los procesos comiciales anteriores. Para garantizar la transparencia en el desarrollo de las etapas del proceso de sorteo de jurados se habilitó el ingreso a la herramienta a los organismos de control y a los ciudadanos designados por los partidos y movimientos políticos para auditar el proceso.

Respecto de los procedimientos de preconteo y escrutinio, para la transmisión de los resultados electorales se desarrolló una aplicación de consulta ciudadana para teléfonos móviles con sistema operativo Android, con información en línea de primera mano que contribuyó al acceso rápido y confiable a los resultados electorales. En la página web de la entidad también se estableció un componente de divulgación y publicación que permitió el acceso a los resultados electorales con diversas ayudas a los ciudadanos como diagramas circulares. Adicionalmente, en abril de 2017 la Registraduría presentó un proyecto de inversión denominado "Implementación prueba piloto de votación electrónica presencial en elecciones atípicas, mecanismos de participación ciudadana y/o en las que la Comisión Asesora de Voto Electrónico determine a nivel nacional" para ser ejecutado en la vigencia 2019.

Si bien no se trata de experiencias de voto electrónico, las actuaciones adelantadas por la Registraduría constituyen un punto de partida para la implementación y crecimiento del gobierno digital en Colombia. El uso progresivo de tecnologías de la información y de las comunicaciones en las etapas anteriores y posteriores al sufragio puede ir generando confianza de 
la ciudadanía, y ha contribuido a la agilidad de los procesos y a evitar tanto fraudes -como la suplantación de los electores- como fallos en los sorteos de jurados de votación. Además, las gestiones adelantadas permiten mirar con optimismo la realización de las nuevas pruebas que hayan de adelantarse durante la vigencia 2019.

\section{CONCLUSIONES}

A pesar de los esfuerzos normativos que se han adelantado en Colombia para implementar mecanismos de voto electrónico en las elecciones nacionales, los costos presupuestarios y la aparente inactividad de la organización electoral se presentan como barreras para la puesta en funcionamiento de herramientas digitales por medio de las cuales los ciudadanos colombianos puedan hacer efectivo su derecho al sufragio activo. Si bien existen mandatos tanto constitucionales como legales para tales efectos, la realidad demuestra que no se ha podido ir más allá de las pruebas que se han implementado.

Esta situación hace que exista una contradicción entre la realidad y el marco normativo establecido para el voto electrónico en el país. En este sentido, siempre se han establecido plazos para la implementación gradual de estas herramientas, términos que no han sido respetados ni cumplidos por la organización electoral debido a los distintos retos y barreras que no solo limitan el uso de tecnologías para los comicios, sino también el actuar del sistema electoral en general.

Siendo la implementación del voto electrónico uno de los tantos retos del funcionamiento del sistema electoral colombiano, debe tenerse en cuenta que esta no solucionará por sí misma los problemas de desconfianza, transparencia y abstencionismo presentes en el país. Sin embargo, el uso de tecnologías puede contribuir a mejorar la confianza de la ciudadanía en el sistema electoral, siempre que se garantice la transparencia y el buen desarrollo de los comicios. Además, la implementación de tecnologías puede facilitar el voto ciudadano, en el sentido de que, dependiendo de cómo se implemente, podría llegar a hacerse desde internet e incluso desde los teléfonos móviles.

De esta forma, la situación de implementación del voto electrónico en Colombia es el reflejo de una tendencia que ha marcado la capacidad de reforma estructural del sistema electoral del país. Convirtiéndose este en uno de los retos que deben ser afrontados para la mejora integral del sistema, el cual, como ya se vio, es de difícil reforma y restructuración. La falta de recursos y de capacitación a la población se asoman como otros de los grandes retos para la implementación de la tecnología en los procesos electorales. En este sentido, no solo es necesario que la organización electoral cuente con la capacidad financiera suficiente para la adquisición y puesta en funcionamiento de las herramientas, sino que también se requiere de la elaboración y 
aplicación de políticas públicas de capacitación a los ciudadanos y de acceso a la información.

No obstante lo anterior, las experiencias internacionales invitan a ser optimistas en cuanto a la implementación del voto electrónico en el país. Puede observarse que, en países vecinos como Brasil y Venezuela, estos mecanismos se han venido implementando de manera continua y con buenos resultados, hasta el punto de que en la actualidad han remplazado a los sistemas de votación tradicionales. Colombia puede aprender de estas experiencias para la implementación de un sistema que cumpla con los estándares constitucionales y permita la unificación del ejercicio del sufragio. A pesar del optimismo, debe reconocerse que el país se encuentra bastante atrasado en la materia, llegando únicamente a hacer pruebas piloto y sin llevar a cabo ningún ejercicio de votación electrónica con carácter vinculante.

Sin embargo, es preciso tener en cuenta los esfuerzos adelantados por las autoridades electorales al implementar medios electrónicos en las etapas pre y post-electorales, las cuales han contribuido a una mayor agilidad en el conteo de los votos, a disponer de herramientas más eficientes de identificación de votantes y de sorteo de jurados de votación y a evitar fraudes electorales. Si bien no se trata propiamente de mecanismos de voto electrónico, sí son medidas de gobierno digital que contribuyen al cumplimiento de los estándares internacionales sobre gobierno digital y que pueden generar mayor confianza de la ciudadana en las autoridades electorales.

También ha de destacarse el mandato contenido en el Acuerdo Final de Paz para implementar herramientas digitales en las votaciones que garanticen una mayor transparencia del debate electoral. Sin embargo, dicha situación resulta similar a las anteriores experiencias vividas en el país, en las cuales se ha regulado de manera amplia el tema pero nunca se han adelantado acciones o políticas de implementación, quedando todo en letra muerta y dando la sensación de que no se dará cumplimiento efectivo a dichos mandatos constitucionales y legales. Habrá que observar de qué manera la organización electoral dará cumplimiento a estos mandatos, esperando que sean superadas las barreras que impiden la implementación efectiva del voto electrónico en Colombia.

\section{REFERENCIAS}

Álvarez, R. M. y Hall, T. E. Electronic Elections: The Perils and Promises of Digital Democracy. Princeton University Press, 2008.

Álvarez, R. M., Katz, G. y Pomares, J. The Impact of New Technologies on Voter Confidence in Latin America: Evidence from e-Voting Experiments in Argentina and Colombia. En Journal of Information Technology \& Politics. 2011. 
Barrat i Esteve, J. Observación electoral y voto electrónico. En Revista Catalana de Derecho Público. N. ${ }^{\circ}$ 39, 2009.

Celeste, R. F. et al. Asking the Right Questions about Electronic Voting. National Academies Press, 2006.

Cuervo Rubio, A. F. Las leyes estatutarias en el ordenamiento jurídico colombiano. Bogotá: Universidad Externado de Colombia, 2017.

Enguehard, Сh. Los dispositivos de voto electrónico "verificables". En Guglielmi, G. J. e Ihl, O. (eds.), El voto electrónico. Madrid: Centre de Droit Public Comparé, Université Panthéon-Assas, 2017.

Guglielmi, G. J. e Ihl, O. (eds.). El voto electrónico. Madrid: Centre de Droit Public Comparé Université Panthéon-Assas, 2017.

Hill, E. Some Thoughts on e-Democracy as an Evolving Concept. En Journal of eGovernment. 1, 1, 2004.

Prandini, M. y Ramilli, M. En e-Service Journal. Vol. 8, n. ${ }^{\circ}$ 3, 2012.

Reniu Vilamala, J. M. Demasiados talones para un solo Aquiles. En Cotarelo, R. y Olmeda. J. A. (eds.), La democracia del siglo XXI: política, medios de comunicación, internet y redes sociales. Madrid: Centro de Estudios Políticos y Constitucionales, 2014.

Reyes González, G. F. La democracia en la era digital: el voto electrónico y por internet como refuerzo de la confiabilidad de los sistemas electorales modernos. Medellín: Diké, 2015.

Reyes González, G. F. Régimen electoral y de partidos políticos en Colombia. 2. ed. Bogotá: Konrad Adenauer Stiftung, 2007.

Romero Flores, R. y Téllez VAldés, J. A. Voto electrónico, derecho y otras implicaciones. México: Universidad Nacional Autónoma de México, 2010.

Ruiz Zúñiga, M. M. El voto electrónico. En Temas selectos de derecho. Vol. 2. Derecho electoral. México: Universidad de Xalapa, 2014.

SÁnchez Torres, C. A. Transparencia, modernización y voto electrónico en la Registraduría Nacional. En Araúuo Oñate, R., Retos y tendencias del derecho electoral. Bogotá: Universidad del Rosario, 2014.

Springall, D. et al. Security Analysis of the Estonian Internet Voting System. Ann Arbor: University of Michigan.

Tuesta Soldevilla, F. El voto electrónico. En Zovatto, D. et al., Tratado de derecho electoral comparado de América Latina. México: Fondo de Cultura Económica, 2011.

Vanegas Gil, P. P. Estudios de derecho electoral. Bogotá: Universidad Externado de Colombia, 2008. 